\title{
Turbulence characteristics of open channel flow over non-equilibrium 3-D mobile dunes
}

\author{
PRASHANTH REDDY HANMAIAHGARI ${ }^{1, *}$ and RAM BALACHANDAR ${ }^{2}$ \\ ${ }^{1}$ Department of Civil Engineering, Indian Institute of Technology Kharagpur, Kharagpur 721302, India \\ ${ }^{2}$ Department of Civil and Environmental Engineering, University of Windsor, 401 Sunset Ave, Windsor, \\ ON N9B 3P4, Canada \\ e-mail: hpr@civil.iitkgp.ernet.in; rambala@uwindsor.ca
}

MS received 7 December 2015; revised 21 February 2016; accepted 15 April 2016

\begin{abstract}
This paper reports velocity measurements over mobile dunes using an acoustic Doppler velocimetry (ADV). Experiments were conducted with two different flow conditions resulting in the formation of two different size mobile dunes. Dunes height, wavelength and velocity of dunes found to be increasing with increase in average flow velocity for a constant flow depth. The quasi-stationary bed condition was assumed while measuring the velocity distribution along the depth. The effect of the non-equilibrium mobile dunes on the flow characteristics and turbulence is examined by computing turbulent intensities, turbulent kinetic energy and Reynolds shear stresses using time averaged and time-space averaged velocity measurements. The magnitudes of transverse velocities are approximately $1 / 10$ of streamwise velocities and vertical velocities are approximately half of the transverse velocities. The considerable magnitudes of transverse velocities over mobile bedforms necessitate measurement of 3-D velocity components to analyze the flow field. Computed turbulence intensities are found to be maximum in the region consisting of the trough and the reattachment point of the dunes. It is observed that streamwise turbulence intensities near the bed are twice the transverse turbulence intensities, and transverse turbulence intensities are twice the vertical turbulence intensities. Reynolds stresses (transverse fluxes of streamwise and vertical momentum) are observed to be high on mobile bedforms which shows mobile dunes reinforce the secondary currents. Peak values of turbulent kinetic energy (TKE) and Reynolds stresses are also found in the region consisting of the trough and the reattachment point. It is visually observed in the present experiments that maximum erosion takes place at the reattachment point and eroded sediment is carried as total load and dropped on the lee slope of the subsequent downstream dune. This phenomenon is caused by flow expansion in the separation zone, and which is also the main reason for mobility of dunes and associated bedload transport. Most importantly, it is found that turbulence anisotropy increases with increase in size of mobile bedforms and anisotropy is extended up to the free surface in the flows over mobile bedforms, which proves the entire depth of flow is being disturbed by the mobile dunes.
\end{abstract}

Keywords. Mobile bedforms; sediment transport; turbulence; bed shear stress; open channel flow; ADV.

\section{Introduction}

Bedforms are common features in alluvial rivers where bedload transport is a dominant phenomenon. The Bedform is also formed at immediate downstream of a scour hole caused by either a transverse obstruction in river flow [1] or a wall jet. Their presence can influence flow friction, bed shear stress, sediment transport capacity and bank stability. Non-equilibrium bedforms may change uniform flow to a gradually varied flow, which is cumbersome to compute in rivers with flood banks [2]. Bedform dynamics affects the overlying flow and alters turbulence fluctuations, which in turn contribute to continuous deformation of the bed. In

*For correspondence time, bedforms continue to evolve and eventually may reach equilibrium (constant size and wavelength). The geometry of the bedforms depends on the mean flow and sediment properties. Bedforms such as dunes, antidunes and chutes, and pools influence the sediment carrying capacity, and also the flood discharge of a river. Therefore, it is necessary to know the hydrodynamic behavior of river flows during the occurrence of bedforms.

As a first step, to comprehend the effect of the dunes on the overlying flow field and its turbulence structure, laboratory studies have been carried out over fixed 2-D dunes by Bennett and Best [3], Balachandar and Patel [4] among many others. When the dunes are formed, flow detaches at the dune crest and immediately downstream of the dune a recirculation (separation) region is formed. The separation 
zone extends four to six dune heights. In the flow separation region, a velocity defect layer is formed, which generates large scale eddies and these eddies move upwards in the flow field and towards the free surface. Downstream of the flow separation region, accelerating flow on the stoss slope develops a new turbulent boundary layer (TBL) which grows until the flow reaches the dune crest. Bennett and Best [3] studied flow past fixed dunes using a LDA and they found occurrence of the highest Reynolds shear stresses along the shear layer triggered by the velocity defect. Bennett and Best [3] while differentiating the dunes and ripples concluded that flow over the dunes is influenced by the strength of the velocity gradient across the shear layer, and strong coherent structures control the local velocities, turbulence and cause the sediment transport. Bennett and Best [5] explained that the velocity defect instability associated with flow circulation on the downstream of the dune crest generates larger scale turbulence, which is advected throughout the flow depth. During this process, ejections in the shear layer contribute maximum to the local Reynolds shear stress while sweep events occur near the separation and reattachment zones. According to Best [6], sweep events exert higher shear stresses on the bed, thereby increasing sediment transport and producing larger bedforms.

Balachandar et al [7] studied the free surface flow over a fixed dunes to understand the influence of flow depth on the turbulence structure. Average velocity, turbulence intensities and Reynolds shear stresses over a fixed 2-D rough dunes have been also investigated by Balachandar and Patel [4] and their analysis revealed the importance of turbulence events such as sweeps near the bed. Balachandar and Patel [4] concluded that the quantifiable effect of the dune surface roughness was restricted to the inner region while the shape of the bedforms, which influences flow separation, played a major role in the outer region. Balachandar and Bhuiyan [8] showed that higher-order moments and ejection events are prevalent throughout the depth in hydraulically rough open channel flows.

Robert and Uhlman [9] performed experiments on different bedform stages during the transition from ripples to dunes. In their study, the bed was initially flat and with increasing velocity, the fixed bedforms were changed to 2-D ripples, 3-D ripples and 2-D dunes. Concrete molds were created for each type of bedform, and the turbulence and flow field above a fixed bedform was studied using an acoustic Doppler velocimeter (ADV). They found that turbulent intensities and Reynolds stresses gradually increased in the outer region as the bedform changed. Coleman et al [10] studied developing bedforms and used the time-space averaging methodology to highlight and improve the estimation of the bed shear stress for flow over bedforms. Coleman et al [10] found that the overall flow structure was changing, with the outer layer, overlap layer and energy dissipating regions being continually compressed during dune evolution.

Most of the experimental studies on fixed dunes have ignored the changes in flow structure due to bed mobility, permeability, bed porosity, sediment transport and continuous development of the bed morphology. Nikora and Goring [11] showed that flow structure over the sediment bed with bed load is quite different from the flow structure on a fixed bed due to differing boundary conditions. Bridge and Best [12] used hot film anemometry to investigate turbulent flow structure, transport of sediment particles and dynamics of mobile bedforms over the bed transformation from lower regime bedforms to upper regime bedforms. They found intense vertical turbulence intensities near the reattachment region in the dune troughs, which gradually decrease during the change from lower regime to the upper regime bedforms. Bridge and Best [12] also noted that the magnitude of streamwise turbulence intensities increases near the bed on the lee side during the washout of dunes to get transformed into plane beds. Schindler and Robert [13] documented that the transition from ripple to dune increases suspended sediment transport due to the wake generation and shear layer turbulence. They reported that the turbulence intensity attained a maximum value during the changeover from ripples to dunes due to increased activity of the shear layers caused by the larger height of the bedform.

In this paper, the turbulence parameters of flow over mobile bedforms are studied for two different flow conditions. This study is novel and report changes in turbulence structure due to the changes in bed morphology. Dune dynamics govern turbulence in the inner layer, which affects the bedforms geometry, bedform development and mobility. Mean velocity and turbulence intensities at various vertical locations are captured with an ADV. The ADV measurements provide 3-D velocity components during bedform growth. In this study, the effect of bedform mobility on the velocity profiles, von Karman constant, skin friction coefficient and Manning's roughness coefficient is investigated. The paper documents time averaged and time-space averaged velocities, turbulent intensities, Reynolds stresses and TKE during the bedform progression.

\section{Experimental setup and methodology}

Experiments were performed in $12.0 \mathrm{~m}$ long straight rectangular open channel flume. A sand bed that was $5.8 \mathrm{~m}$ long, $0.15 \mathrm{~m}$ thick and spanning the width placed in this flume. A ramp was added at the beginning of the sand bed to enable smooth transition of the flow to the bed. A schematic sketch of the experimental setup is presented in figure 1. The sediment bed consists of sand grains with a median diameter $\left(d_{50}\right)$ of $0.7 \mathrm{~mm}, d_{84}=0.9 \mathrm{~mm}$ and $d_{16}=0.62 \mathrm{~mm}$. The sediment specific gravity was 2.65 . 


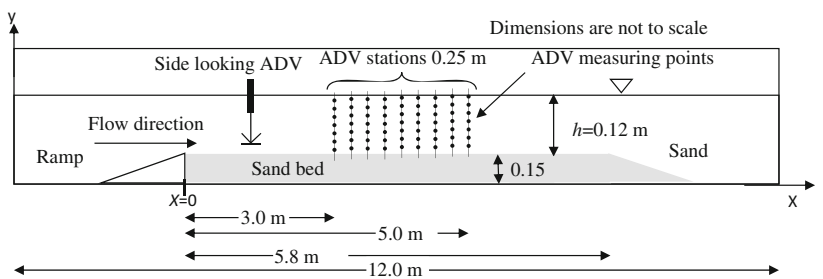

Figure 1. Schematic of the experimental setup.

Water was recirculated using a centrifugal pump with an adjustable flow control. The test reach was located along the flume axis, $x=3.0 \mathrm{~m}$ in the direction of flow from the beginning of the sand bed, i.e., $x=0$. This streamwise location was considered sufficient for the flow to attain a fully developed state and several preliminary experiments were conducted to verify this. Two experiments were conducted and are hereafter referred to as PRMB-1 and PRMB-2, respectively. PRMB stands for porous rough mobile bedforms. The specifics of the experimental conditions are provided in table 1 . The velocity measurements were started $30 \mathrm{~min}$ after the flow was commenced to allow the formation of bedforms. Velocity profiles at nine stations spaced at $0.25 \mathrm{~m}$ apart, along the midsection of the flume were recorded using a side looking Nortek ADV Vectrinoplus system. Nortek downlooking ADV profiler (Vectrino 2) was also used to record the velocities near the bed in PRMB-2, hereafter which is referred as PRMB2ADVP. Schematic of the measurement locations is shown in figure 1.

Nikora and Goring [14] and Chanson et al [15] have described ADV and its use in hydraulic experiments. The ADV was mounted on a two-directional traverse that locates the ADV in streamwise and vertical direction with an accuracy of $0.01 \mathrm{~mm}$. The spatial resolution of the ADV permits measurements within about $5.0 \mathrm{~mm}$ above the bed. The side looking ADV measures the flow velocities in the remote sampled volume at a distance of $0.05 \mathrm{~m}$ away to minimize probe disturbance in the flow. A constant sampling rate of $100 \mathrm{~Hz}$ was selected for all measurements. The velocity data was recorded for $2 \mathrm{~min}$ at each measurement location. Ninety seconds were allowed in between velocity measurements of two consecutive vertical locations to minimize disturbance in the flow due to the movement of ADV probe. It was assumed that the bed does not change significantly (quasi stationary condition applies i.e., flow depth does not change more than 5\%) over the period of the velocity measurements along the depth at a streamwise location. The conclusions presented in the paper may deviate if the flow depth changes rapidly i.e. more than $6 \%$ during the velocity measurements along the depth at a streamwise location. The Cartesian co-ordinate system is adopted in the paper with $x, y$ and $z$ denoting the streamwise, bed-normal and transverse directions and their respective velocity components are denoted as $u, v$ and $w$. The temporal mean values are represented as $\bar{u}, \bar{v}$ and $\bar{w}$ while turbulent intensities are indicated as $u_{\mathrm{rms}}, v_{\mathrm{rms}}$ and $w_{\text {rms }}$ respectively. Similarly, the time and space averaged quantities are represented as $\overline{\bar{u}}, \overline{\bar{v}}$ and $\overline{\bar{w}}$ in $x, y$ and $z$ directions. To analyze the uncertainty of the measurements, samples were taken at a location $70 \mathrm{~mm}$ above the bed at different times after starting the experiments. Computed uncertainty estimates of RMS velocities and the Reynolds shear stresses are $\pm 5 \%$ and $\pm 12 \%$ respectively. Velocities were measured along a vertical line from $y \approx 5 \mathrm{~mm}$ above the bed to $y \approx 30 \mathrm{~mm}$ below the free surface at each measurement station in PRMB-1. However, the lowest height at which measurements were made was $40 \mathrm{~mm}$ directly above the bed in PRMB-2 due to rapid changes in bed profile. The bed continuously deformed while measurements are being taken therefore it is to be noted that the measurements at any two nodes along the vertical are not referenced to the same bed condition in PRMB- 1 and PRMB-2. Nortek Vectrino 2 (profiler) was used in experiment 2 to supplement PRMB-2 to capture the velocities near the bed. The advantage of vectrino profiler is its ability to measure velocities simultaneously at every $1 \mathrm{~mm}$ interval in $70 \mathrm{~mm}$ long sampling volume. In addition, it also measures the distance of the bed from the measuring point so it can be said precisely that Vectrino 2 measures 3D velocities at a point and its vertical distance from the bed. The acceleration threshold method advanced by Goring and Nikora [16], Wahl [17, 18] and Mori et al [19] to despike and filter random noise is used in this study. The guidelines for acceptable level of noise in the signal and cross-correlation as specified by Chanson et al [15] are strictly followed i.e., data points corresponding to SNR value less than $22 \mathrm{~dB}$ and cross-correlation less than 70 are discarded. In these experiments, cross-correlation values are found to be consistently more than $85 \%$; however, data points measured near the bed have the average cross-correlation value of $82 \%$. Instantaneous velocities falling beyond 3.5 standard deviation bound on either side are also removed.

Table 1. Experimental conditions.

\begin{tabular}{lcccc}
\hline Experiments & $\begin{array}{c}\text { Depth of water } \\
h(\mathrm{~m})\end{array}$ & $\begin{array}{c}\text { Time-space averaged velocity } \\
\bar{u}(\mathrm{~m} / \mathrm{s})\end{array}$ & $\begin{array}{c}\text { Maximum velocity } U_{\text {max }} \\
(\mathrm{m} / \mathrm{s})\end{array}$ & $\begin{array}{c}\text { Reynolds number } \\
\operatorname{Re}=\bar{u} h / v\end{array}$ \\
\hline PRMB-1 & 0.12 & 0.49 & 0.59 & 54,900 \\
PRMB-2 & 0.12 & 0.58 & 0.69 & 65,000 \\
\hline
\end{tabular}



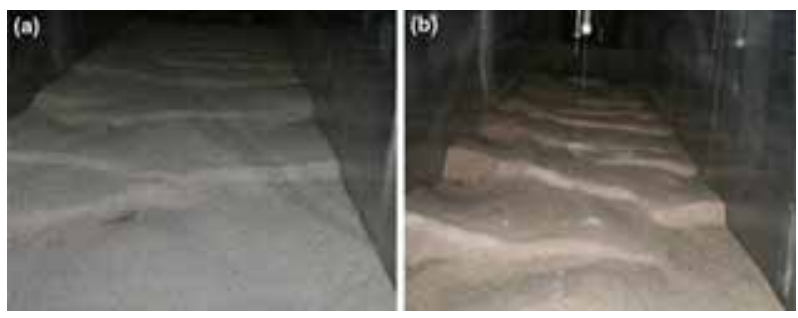

Figure 2. Formation of dunes at $1 \mathrm{~h}$ from the start of the experiment (a) PRMB-1 $\mathrm{Re}=54,900$ and (b) PRMB-2 $\operatorname{Re}=65,000$.

The outlier velocities found to be less than $5 \%$ of the original velocity data and do not have any effect on frequency spectrum. Finally, the results presented here refers to typical flow conditions over mobile bedforms formed in $0.7 \mathrm{~mm}$ sand.

In both experiments, 3-D dunes were formed, stretching across the width of the flume. Pictures of the mobile bedforms in experiments PRMB-1 and PRMB-2 are presented in figure 2. In experiment PRMB-1, average dune height was $0.036 \mathrm{~m}$ and average dune wavelength $=0.44 \mathrm{~m}$ (range $=0.3-0.5 \mathrm{~m})$. Bigger dunes were generated in experiment PRMB-2 (figure 2) due to the increased flow velocity while the initial flow depth was kept same in both the experiments. However, during the experiment flow depth was increased in PRMB-2 because of increased sediment transport. It is believed that flow acceleration on the stoss slope, and flow separation on the lee slope of the dune causes the increase in dune size in PRMB-2. In experiment PRMB-2, the average height of the dune was $0.042 \mathrm{~m}$ and the average dune wavelength was $0.50 \mathrm{~m}$ (range $=0.4-0.6 \mathrm{~m})$. The lee face slopes in the present experiments ranged from 0.5 to 0.75 (ratio of vertical to horizontal). The height and wavelength of the dunes observed in present experiments are similar to the dune profiles observed by Bridge and Best [12].

The pressure drag that results from the transformation of sediment bed into bedforms is far greater than the skin friction of individual sand particles, causing a substantial increase in the overall flow frictional resistance. The peaks and valleys of the dunes were measured using a digital point gauge along the flume centerline in $30 \mathrm{~min}$ intervals. The measured bed profiles for experiment PRMB-2 after 90, 120, 150 and $180 \mathrm{~min}$ are shown in figure 3, where the continuous progression of dunes with time was shown. The bedforms formed in experiments PRMB-1 and PRMB-2 are asymmetrical in the longitudinal direction, with longer stoss side and shorter lee side. It can be seen that some bedforms are in compound form in final bed profile in PRMB-2. In these experiments, bed load was transported in the form of dunes and there was no feed of the sediment back into the flume during the length of the experiment, therefore the sand bed was continuously decreasing with time.

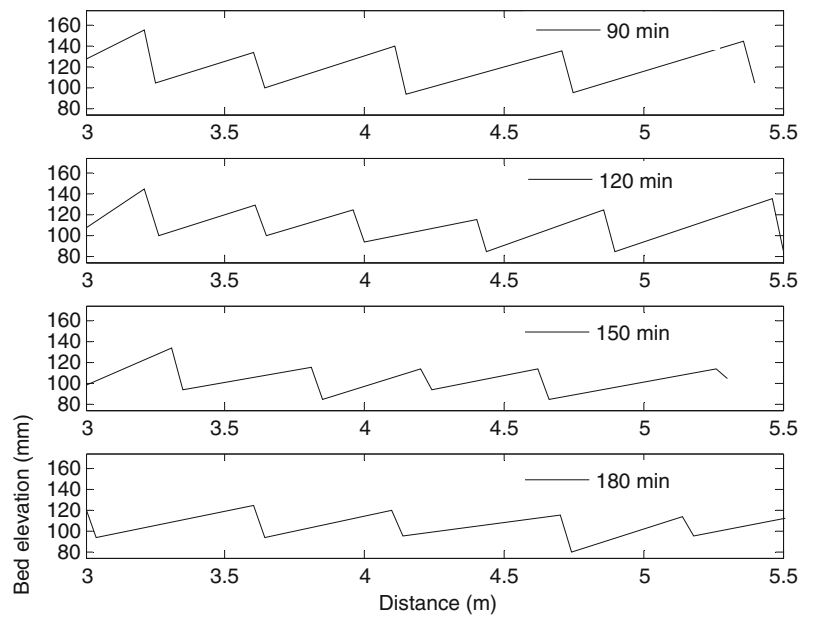

Figure 3. Bedforms propagation at different time intervals in experiment PRMB-2.

\section{Results and discussion}

\subsection{Friction factor}

The von Karman constant $\kappa$ relates the distribution of flow velocity and friction velocity. The reported $\kappa$ values varied between 0.43 and 0.37 for hydraulically rough and smooth open channel flows [11]. Recent paper of Nikora and Goring [11] observed a diminution in the Karman's dimensionless constant in mobile bed experiments, whereas, Gyr and Schmid [20], and Song et al [21] do not confirm the change in von Karman constant under mobile bed conditions. By using the traditional value of $\kappa$, it was found that the classical logarithmic law is not applicable to flows with bedform motion. Therefore, $\kappa$ was evaluated using the present experimental data. The following equation [11] has been used to compute von Karman constant and surface roughness for each experiment.

$$
\bar{u}=\frac{u_{*}}{\kappa} \ln \left(\frac{y}{y_{o}}\right) .
$$

Here, $\bar{u}$ is the mean velocity at an elevation $y$ above the reference bed, $u_{*}$ is the friction velocity, $y=$ vertical coordinate away from the reference bed; $y_{o}$ is the location of zero velocity. Velocity distribution bounded by $0.05 \leq y / h \leq 0.7$ is used to best fit the experimental data and determine $\kappa$ and $y_{o}$. The values of the friction velocity denoted as $u_{*}$ can be directly estimated for the fully developed turbulent flow using extrapolation of linear regression of the Reynolds shear stress in the outer region $0.2<y / h<0.7$ free of the viscous stresses [11, 22]. The computed values of $\kappa$ and $u_{*}$ of the present experiments are presented in tables 2 and 3. The estimated $\kappa$ values are in between 0.2 and 0.35 for mobile bedforms. The results illustrate the decrease in von Karman constant due to increased thickness of roughness sublayer as the mobility of bedforms increases. The other reasons for reduced $\kappa$ value 
Table 2. Flow turbulence parameters in experiment PRMB-1.

\begin{tabular}{lccccccccc}
\hline & & & & & & (Eq. 3) & (Eq. 4) & \\
Location $x=(\mathrm{m})$ & $\bar{u}$ & $u_{*}$ & $\kappa$ & $\Pi$ & $\Delta u^{+}$ & $k_{s}^{+}$ & $k_{s}^{+}$ & $f$ & Manning's coefficient \\
\hline 3.00 & 0.53 & 0.028 & 0.28 & -0.36 & 12.59 & 81 & 29 & 0.023 & 0.011 \\
3.25 & 0.51 & 0.028 & 0.29 & -0.34 & 11.48 & 72 & 31 & 0.024 & 0.012 \\
3.50 & 0.48 & 0.026 & 0.27 & -0.37 & 12.50 & 72 & 27 & 0.024 & 0.012 \\
3.75 & 0.50 & 0.030 & 0.27 & -0.35 & 13.84 & 101 & 39 & 0.029 & 0.013 \\
4.00 & 0.46 & 0.026 & 0.30 & -0.36 & 11.75 & 84 & 29 & 0.027 & 0.012 \\
4.25 & 0.41 & 0.028 & 0.34 & -0.38 & 9.94 & 82 & 44 & 0.037 & 0.015 \\
4.50 & 0.49 & 0.031 & 0.32 & -0.36 & 10.34 & 80 & 45 & 0.032 & 0.013 \\
4.75 & 0.55 & 0.030 & 0.29 & -0.37 & 12.02 & 78 & 33 & 0.024 & 0.012 \\
5.00 & 0.52 & 0.032 & 0.31 & -0.33 & 10.85 & 75 & 43 & 0.029 & 0.013 \\
Average & 0.49 & 0.029 & 0.30 & -0.36 & 11.70 & 81 & 36 & 0.028 & 0.012 \\
\hline
\end{tabular}

Table 3. Flow turbulence parameters in experiment PRMB-2ADVP.

\begin{tabular}{lccccccccc}
\hline Location $x=(\mathrm{m})$ & $\bar{u}$ & $u_{*}$ & $\kappa$ & $\Pi$ & $\Delta u^{+}$ & (Eq. 3) $k_{s}^{+}$ & (Eq. 4) $k_{s}^{+}$ & $f$ & Manning's coefficient \\
\hline 3.00 & 0.66 & 0.040 & 0.28 & -0.10 & 23.21 & 1628 & 81 & 0.030 & 0.013 \\
3.25 & 0.62 & 0.042 & 0.28 & 0.00 & 21.66 & 1055 & 139 & 0.036 & 0.043 \\
3.50 & 0.59 & 0.043 & 0.28 & 0.00 & 21.61 & 1039 & 103 & 0.037 & 0.015 \\
3.75 & 0.58 & 0.040 & 0.28 & 0.00 & 22.57 & 1360 & 175 & 0.050 & 0.016 \\
4.00 & 0.57 & 0.045 & 0.28 & 0.00 & 25.53 & 3118 & 131 & 0.044 & 0.017 \\
4.25 & 0.56 & 0.042 & 0.28 & 0.00 & 24.94 & 2639 & 320 & 0.071 & 0.020 \\
4.50 & 0.54 & 0.050 & 0.28 & 0.00 & 23.38 & 1705 & 213 & 0.058 & 0.019 \\
4.75 & 0.53 & 0.046 & 0.28 & 0.00 & 22.93 & 1506 & 343 & 0.073 & 0.021 \\
5.00 & 0.53 & 0.051 & 0.28 & 0.00 & 20.82 & 2383 & 179 & 0.049 & 0.017 \\
Average & 0.58 & 0.044 & 0.280 & -.011 & 22.96 & 1826 & &
\end{tabular}

are non-uniform flow, secondary flows, bed permeability and mobile bedforms.

Velocity defect equation in a fully grown hydraulically rough TBL in a fluid flow proposed by Krogstad et al [23] is used to compute wake parameter $(\Pi)$ and shift in the origin $(\varepsilon)$ by optimizing the velocity profile measured in the outer layer $y / h>0.1$. The non-dimensional wake parameter $\Pi$ is an indicator of the nonconformity of the measured velocities from the logarithmic law of the wall. The estimated $\Pi$ values (see tables 2 and 3 ) varied between -0.36 and -0.011 in PRMB-1 and PRMB-2, respectively. Holmes and Garcia [24] found that wake parameter ranges from -0.251 to -0.127 on the lee side of bedforms. Wake parameter depends on the pressure gradient in non-uniform flows, its value is negative since the flume is horizontal and accelerating flows are taking place in the present experiments. As the bedforms size is growing from PRMB-1 to PRMB-2 the wake parameter is increasing which reflects that the flow is less accelerated.

Downward shift $\left(\Delta u^{+}\right)$in the logarithmic law in a turbulent boundary layer formed on a rough bed may be obtained by applying the following Coles velocity defect law to measured velocity distribution [25].

$$
\frac{u}{u_{*}}=\frac{1}{\kappa} \ln \frac{(y+\varepsilon) u_{*}}{v}+B-\Delta u^{+}+\frac{2 \Pi}{\kappa} \sin ^{2}\left(\frac{\pi(y+\varepsilon)}{2 h}\right) .
$$

In Eq. (2), $\Pi$ is the wake parameter; $h$ is water depth. Equation (2) was used to compute $\Delta u^{+}$since all other variables in Eq. (2) are known. The computed $\Delta u^{+}$values are listed in tables 2 and 3 . The computed $\Delta u^{+}$values are very high $\left(\Delta u^{+}>10.0\right)$ for mobile bedforms. Velocity shift is higher in PRMB-2 as compared to PRMB-1 experiments. The equivalent sand grain roughness $\left(k_{s}^{+}\right)$was also calculated from the equations given by Raupach et al [26] and Camenen et al [27], and the values are presented in tables 2 and 3. It is found that the correlation provided by Camenen et al [27] underestimates the $k_{s}^{+}$of mobile bedforms whereas Raupach et al [26] formula appears to be giving correct values of equivalent sand grain roughness. The equations to estimate $k_{s}^{+}$given by Raupach et al [26] and Camenen et al [27] are given below for ready reference.

Raupach et al [26] formula:

$$
k_{s}^{+}=\exp \left(\Delta u^{+}+3.2\right) \kappa
$$

where $\Delta u^{+}$is downward shift in the log-law and $\kappa$ is von Karman constant. 
Camenen et al [27] formula:

$$
k_{s}^{+}=\frac{d_{50}\left(0.6+1.8 V_{s *}^{1.2} F^{-2.4} \theta^{1.7}\right) u_{*}}{v}
$$

where

$$
V_{s *}=\frac{V_{s} R^{2 / 3}}{(g v)^{1 / 3}} ; R=\frac{\rho_{s}}{\rho}-1 ; F=\frac{U}{\sqrt{g h}}, \theta=\frac{u_{*}^{2}}{R g d_{50}} .
$$

The flow is completely rough in the case of mobile bedforms $\left(k_{s}^{+}>70\right)$. The computed Manning's roughness coefficients, skin friction coefficients and Darcy Weisbach friction factors are presented in tables 2 and 3. For the same bed without bed movement (immobile bed) the computed values of Manning's coefficient $=0.009$, skin friction coefficient $=0.004$ and Darcy friction factor $=0.016$. Whereas, in PRMB-1, the computed values of Manning's coefficient, skin friction coefficient and Darcy friction factor are 0.012, 0.0069 and 0.028 , respectively. It is observed that friction factor increases from immobile bed condition to mobile bedforms. In PRMB-2 experiment, the computed values of Manning's coefficient, skin friction coefficient and Darcy friction factor are $0.017,0.012$ and 0.049 , respectively. The increase in resistance coefficients from PRMB-1 to PRMB-2 indicates that bed friction is proportional to mobile bedforms size and velocity for a given flow depth. It is to be noted that the steepness factors (ratio of dune height to dune wave length) of bedforms in two mobile bedforms experiments namely PRMB-1 and PRMB-2 are approximately the same which confirms that for a given flow depth, bed friction is only a function of bedforms size and velocity of bedforms and independent of steepness factor of bedforms.

\subsection{Velocity profiles}

Figures 4(a), 4(b) and 4(c) show the temporal mean streamwise velocity profiles at different stations for PRMB-1 and PRMB-2. The solid circles in figures 4(a) and 4(b) represent the actual bed elevation at the start of the velocity measurements at that vertical location. It was observed that the bed does not change significantly (quasi stationary condition applies) over the period of the velocity measurements at a location. Figures (4a), (4b) and (4c) reveal that streamwise velocities are positive throughout the depth in all vertical profiles. Streamwise velocities are accelerated on stoss side and maximum flow velocities are reached in the outer layer on the crest as observed at locations $3.0 \mathrm{~m}$ and $4.75 \mathrm{~m}$ in figure 4(a) and location $3.25 \mathrm{~m}$ in figure 4(b). Streamwise velocities are decelerated on lee side thus attaining lowest velocities due to expansion of flow near the trough as observed at location $4.25 \mathrm{~m}$ in figure $4(\mathrm{a}), 4.75 \mathrm{~m}$ in figure 4(b) and $3.0 \mathrm{~m}$ in figure 4(c). Dune lee side is passing under the ADV probe at $4.25 \mathrm{~m}$ thereby increases the bed elevation which might have caused decrease in the velocity at $5 \mathrm{~mm}$ above the location (figure 4a). Similarly, velocity is also decreased at
$5 \mathrm{~mm}$ above the bed at location $4.75 \mathrm{~m}$ (figure $4 \mathrm{a}$ ) due to expansion of flow caused by the passing of crest under ADV probe. Figure 4(c) shows the near bed velocities in experimental flow conditions similar to PRMB-2 but velocities were measured with a downlooking ADV profiler. Bridge and Best [12] lower streamwise velocities near the bed in flows over mobile bedforms due to increased form drag associated with the porous mobile bedforms which is supported by the decrease in velocities near the mobile bedforms at locations $x=3.75,4.25,4.75$ and $5.0 \mathrm{~m}$ (figure $4 \mathrm{c}$ ).

Figures 5(a), 5(b) and 5(c) illustrate the time averaged measured transverse velocity components at different locations for PRMB-1 and PRMB-2. The time averaged transverse velocities are positive throughout the depth at most of the locations in PRMB-1 and PRMB-2. Transverse velocities are positive near the bed on crest and on the stoss side. Transverse velocity profiles become negative near the water surface at $x=3.75,4.0$ and $4.25 \mathrm{~m}$ due to free surface effect in PRMB-2 (figure 5b). Transverse velocities are higher in dune trough and dune crests [figures 5(a) and $5(\mathrm{c})]$ and they are of the order of $0.1 \mathrm{~m} / \mathrm{s}$ close to the bed in dune trough and $0.05 \mathrm{~m} / \mathrm{s}$ near the bed on the dune crest [refer to figure 5(a) and figure 5(c)]. Figure 5c shows prevalence of high transverse velocities in the dune trough at $x=4.0 \mathrm{~m}$ and also at the beginning of the stoss slope at $x=4.25 \mathrm{~m}$. Strong transverse velocities indicate the presence of secondary currents at those locations.

Figures 6(a), 6(b) and 6(c) show time averaged vertical velocity components in spatial test reach in experiments PRMB-1, PRMB-2 and PRMB-2ADVP. Vertical velocities are negative throughout the depth in the crest and trough regions. High vertical velocities were observed in dune troughs at $x=4.25 \mathrm{~m}$ as shown in figure 6(a) and figure $6(\mathrm{c})$ and their values are around $-0.05 \mathrm{~m} / \mathrm{s}$. It is inferred that streamlines are directed downwards throughout the depth in crest and trough regions. The streamline behavior in present experiments is similar to the flow turbulence over rough beds. Vertical velocities in PRMB-1 and PRMB-2 are comparable to transverse velocities. Vertical velocities are small in the middle of the stoss slope as shown in figure $6(\mathrm{c})$. Vertical velocities are large only near the bed due to changes taking place in bed profile and their values are small after one dune height above the bed. Vertical velocities are very small over the dune crests as observed at $x=3.75 \mathrm{~m}$ and $x=4.75 \mathrm{~m}$ in figure 6(c). Measured high vertical velocities in dune troughs and low vertical velocities on dune crests point out the activity of high erosion in dune troughs.

The absolute magnitude of depth averaged vertical velocity is less than the depth averaged transverse velocity at any section. The velocity magnitudes are in the order of $\mid$ streamwise velocity $u|>|$ transverse velocity $w|>|$ vertical velocity $v$ on mobile dunes. The magnitudes of transverse velocities are approximately $1 / 10$ of streamwise velocities. Vertical velocities are approximately one-half of the transverse velocities. The considerable magnitudes of 


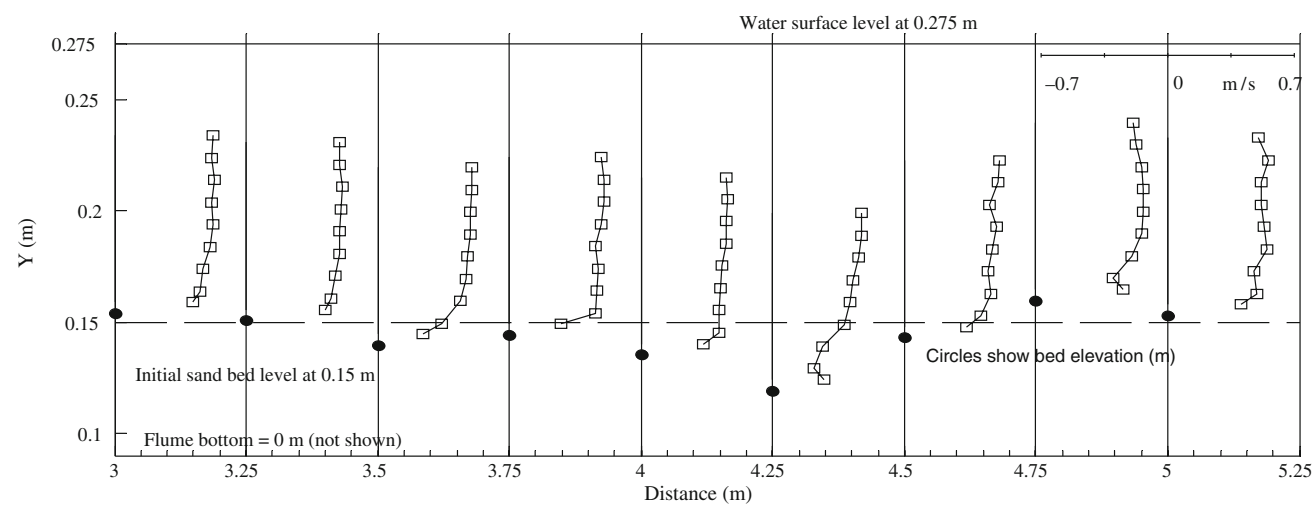

(a)

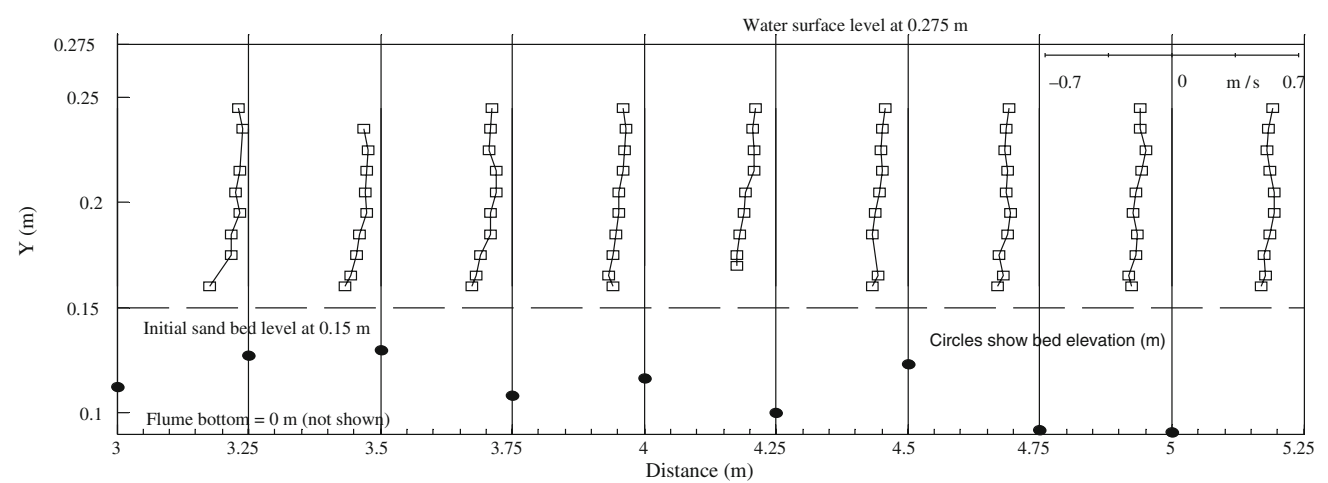

(b)

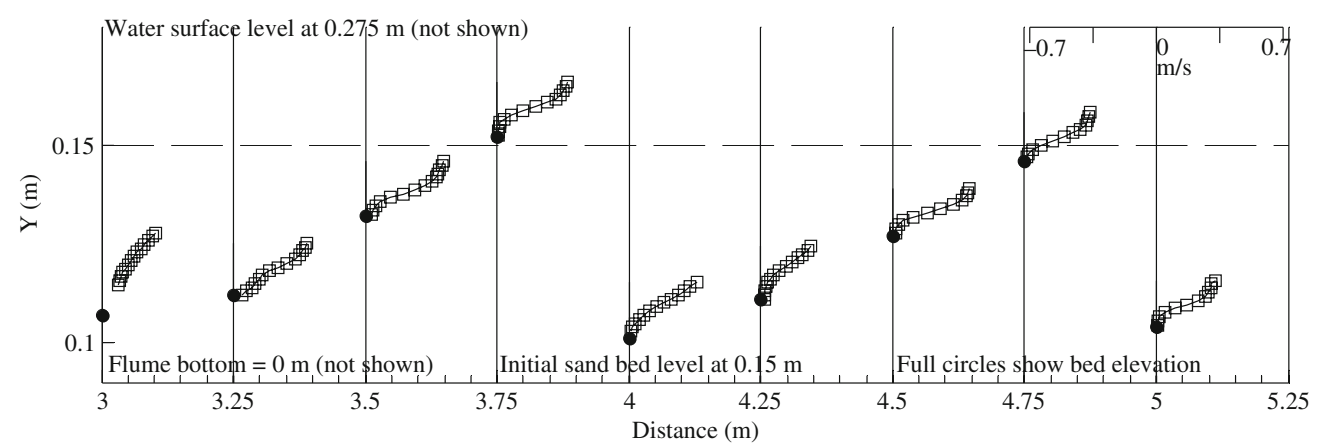

(c)

Figure 4. Mean streamwise velocity profiles (a) PRMB-1, (b) PRMB-2, and (c) PRMB-2ADVP.

transverse velocities along the depth illustrate the 3-D characteristic of the flow field over the mobile bedforms.

\subsection{Turbulence intensities}

Maximum $u_{\text {rms }}, w_{\text {rms }}$ and $v_{\text {rms }}$ magnitudes are occurring in the trough above the recirculation region in the velocity defect layer (figures 7, 8 and 9) and decreasing along the stoss slope which shows prevalence of high turbulence in the trough region and increasing three dimensionality of the flow field due to continuous erosion (figure 7c). Transverse turbulent intensities $\left(w_{\text {rms }}\right)$ increasing near the dune crest (figure 8c) whereas vertical turbulence intensities attain lowest on the dune crest (figure 9c). The peak values of $v_{\text {rms }}$ in both the experiments lies between 20 and $40 \%$ of corresponding $u_{\mathrm{rms}}$ and $50-60 \%$ of $w_{\text {rms }}$ values. The range of normalized $v_{\text {rms }}$ values in PRMB-2 and PRMB-1 are 0.040.086 , and $0.04-0.12$ respectively compares favorably with the reported vertical turbulence intensities of $0.1-0.2$ [5] over the dunes. The actual $v_{\text {rms }}$ values in present experiments are $0.03-0.06 \mathrm{~m} / \mathrm{s}$ compare well with the 0.04 $0.045 \mathrm{~m} / \mathrm{s}$ suggested by Robert and Uhlman [9] and $0.034 \mathrm{~m} / \mathrm{s}$ as given by Bennett and Best [3] over 2-D dunes. Maximum vertical turbulence intensities are occurring far away from the bed at section $x=4.50 \mathrm{~m}$ (trough region) 


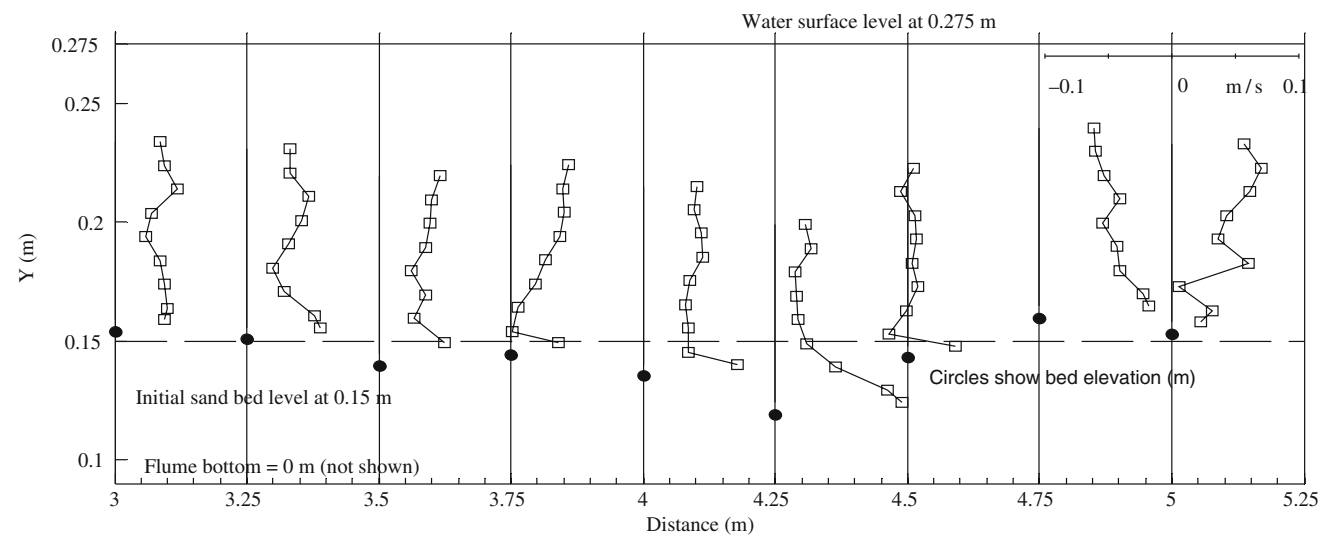

(a)

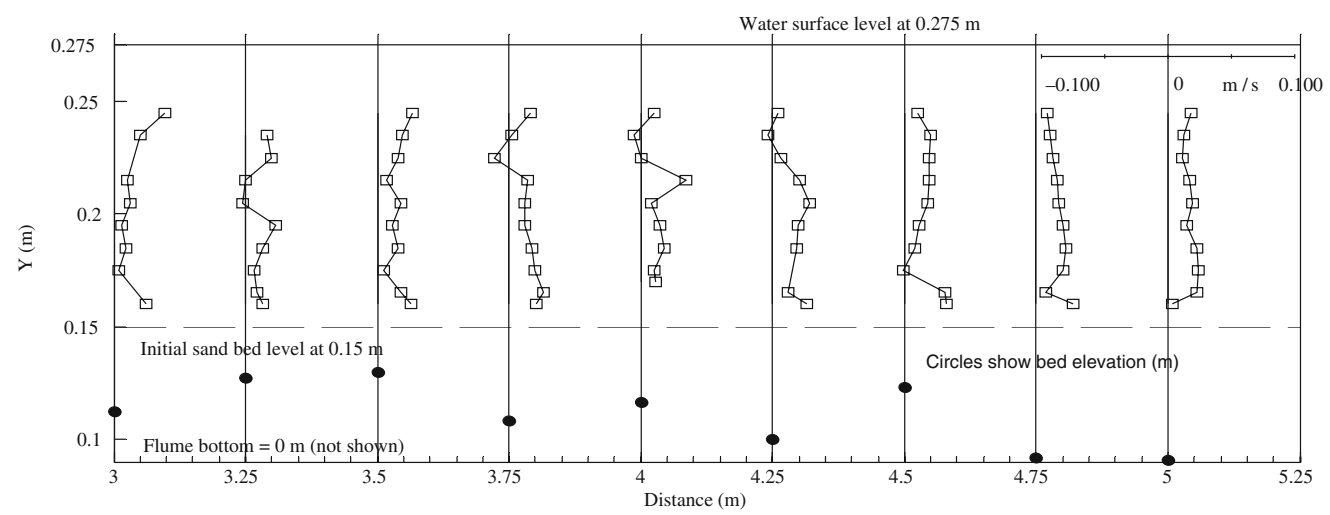

(b)

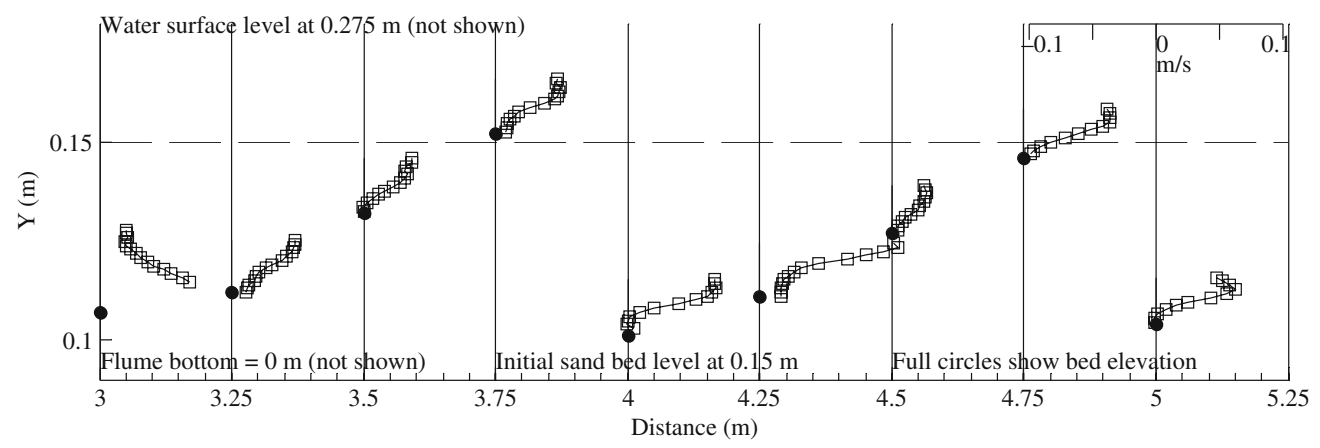

(c)

Figure 5. Profiles of mean transverse velocities (a) PRMB-1, (b) PRMB-2, and (c) PRMB-2ADVP.

may be due to the wake effect (figure 9a). The $u_{\mathrm{rms}}, v_{\mathrm{rms}}$ and $w_{\text {rms }}$ are increasing until $y / h=0.1$ then decreasing for $y / h>0.1$, which could be due to existence of form roughness boundary layer on the mobile bedforms (see figures 7-9). The region of high $w_{\text {rms }}$ magnitudes (between 0.055 and $0.07 \mathrm{~m} / \mathrm{s}$ ) spread from the dune trough to dune crest, completely encapsulating the internal boundary layer on the stoss side (see sections $x=4.0,4.25 \mathrm{~m}$ and $4.5 \mathrm{~m}$ in figure 8a). Low $w_{\text {rms }}$ values (from 0.01 to $0.03 \mathrm{~m} / \mathrm{s}$ ) are occurring within the region of flow recirculation on the dune lee-face (figure 8a). Analysis of 3-D turbulence intensities reveals that turbulence is very high in the region consisting of dune lee side, trough and reattachment.

\subsection{Reynolds stresses}

Vertical distributions of Reynolds stresses measured in PRMB-1 and PRMB-2 are shown in figures 10-12. Reynolds stresses $-\overline{u^{\prime} v^{\prime}},-\overline{v^{\prime} w^{\prime}}$ and $-\overline{u^{\prime} w^{\prime}}$ first increase and attain peak values within the shear layer due to prevalence of sweeps then decrease and finally reaches a lowest value at the water surface (figure 10). The peak values of Reynolds stress $-\overline{u^{\prime} v^{\prime}}$ (bed roughness) are occurring on the dune crest which is similar in magnitude in PRMB-1 and PRMB-2 [refer figures 11(a) and 11(c)] which indicates occurrence of high bedload and suspended load. Reynolds stress $-\overline{u^{\prime} v^{\prime}}$ attains a maximum value at $y / h=0.1$ in the 


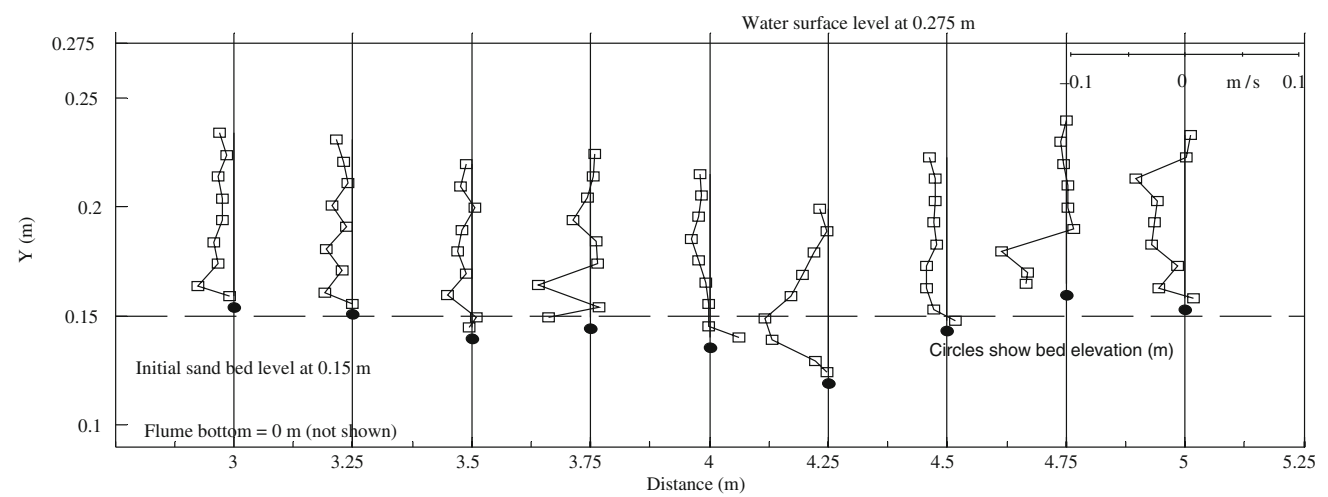

(a)

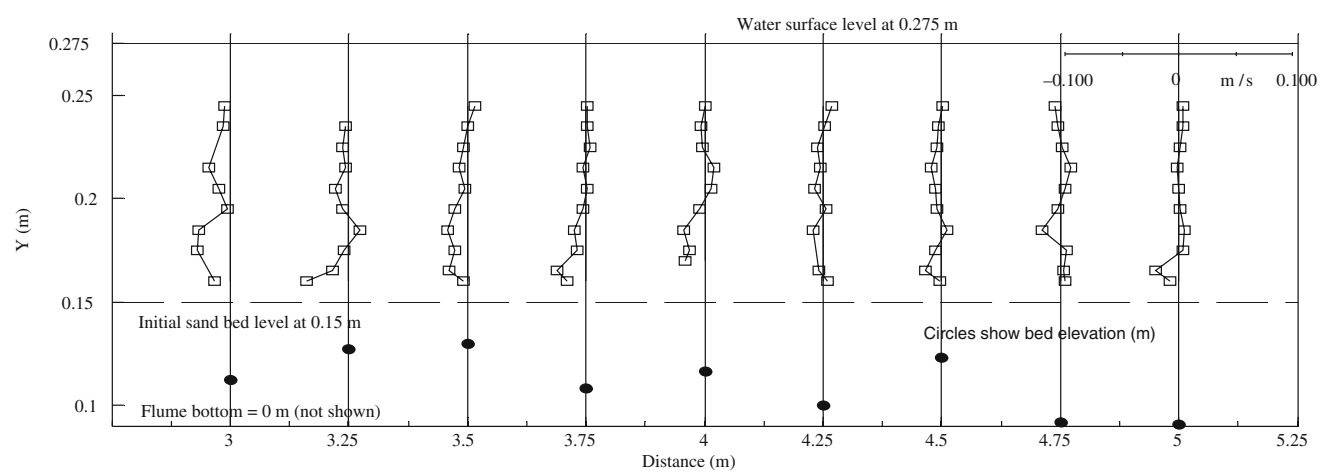

(b)

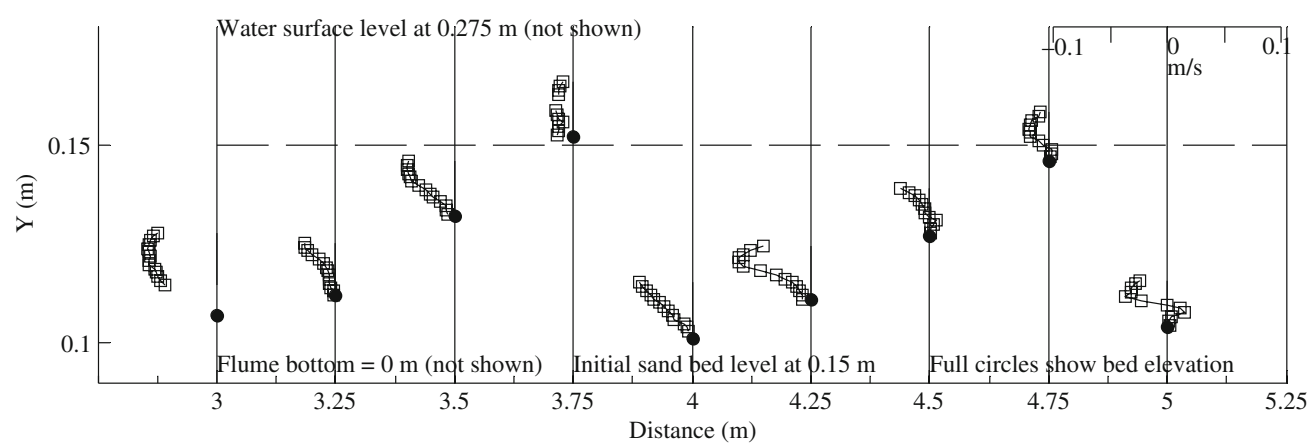

(c)

Figure 6. Profiles of vertical velocities (a) PRMB-1, (b) PRMB-2, and (c) PRMB-2ADVP.

trough and at the height of $y / h=0.2$ on the dune crest where turbulence is caused by the flow separation (figures 11a and 11c). Reynolds stresses $-\overline{v^{\prime} w^{\prime}}$ (transverse flux of vertical momentum) and $-\overline{u^{\prime} w^{\prime}}$ (transverse flux of streamwise momentum) represent secondary motions in mobile bedforms, according to Nezu and Nakagawa [22], non-uniform roughness of the channel causes secondary motions. Reynolds stress $-\overline{v^{\prime} w^{\prime}}$ values are found to be higher in PRMB-2 (figure 12b). Finally, it is concluded that Reynolds shear stress increases considerably at both crest and trough locations in mobile dunes (maximum $-\overline{u^{\prime} v^{\prime}}$ is $0.0024 \mathrm{~m}^{2} / \mathrm{s}^{2}$ ). Reynolds stress $-\overline{u^{\prime} v^{\prime}}$ is positive whereas $-\overline{u^{\prime} w^{\prime}}$ is negative throughout the depth as observed in figure 10a. Reynolds stress $-\overline{u^{\prime} w^{\prime}}$ attains a negative peak near the bed in dune troughs and reattachment region on stoss side (sections $x=4.0,4.25 \mathrm{~m}$ as shown in figure 10c). The trend of Reynolds stress $-\overline{u^{\prime} w^{\prime}}$ is similar in the upper region of stoss slope and crest (figure 10c). Similarly, the trend of Reynolds stress $-\overline{u^{\prime} w^{\prime}}$ is similar in the region of reattachment and trough (figure 10c). There is no considerable variation in the behavior of $-\overline{v^{\prime} w^{\prime}}$ across the dune wave length (figure 12c). The order of absolute magnitudes of Reynolds stresses on mobile bedforms is $-\overline{u^{\prime} v^{\prime}}>-\overline{u^{\prime} w^{\prime}}>-\overline{v^{\prime} w^{\prime}}$ 


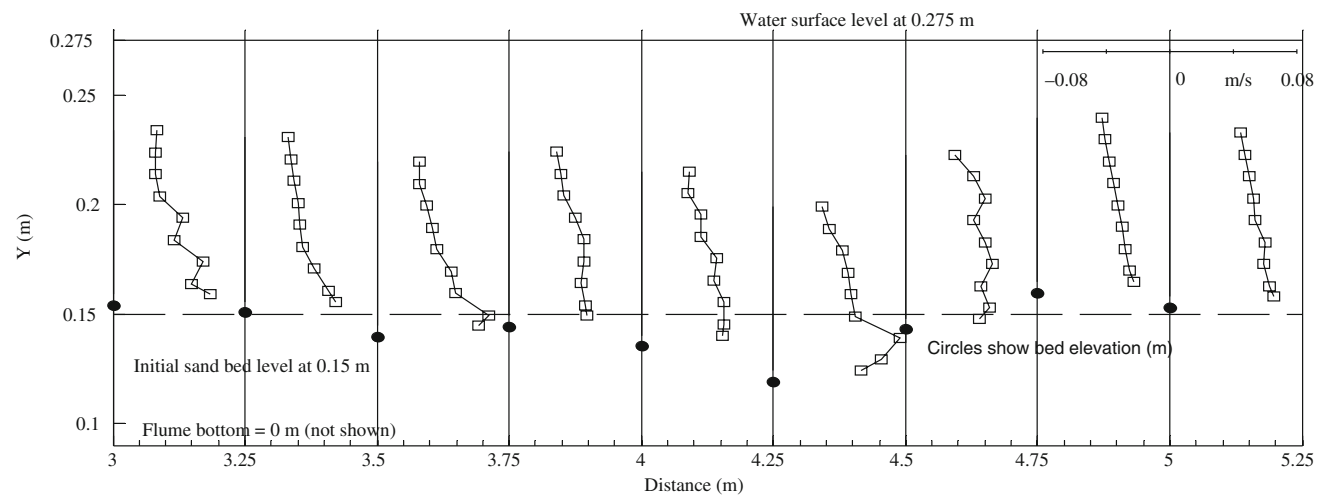

(a)

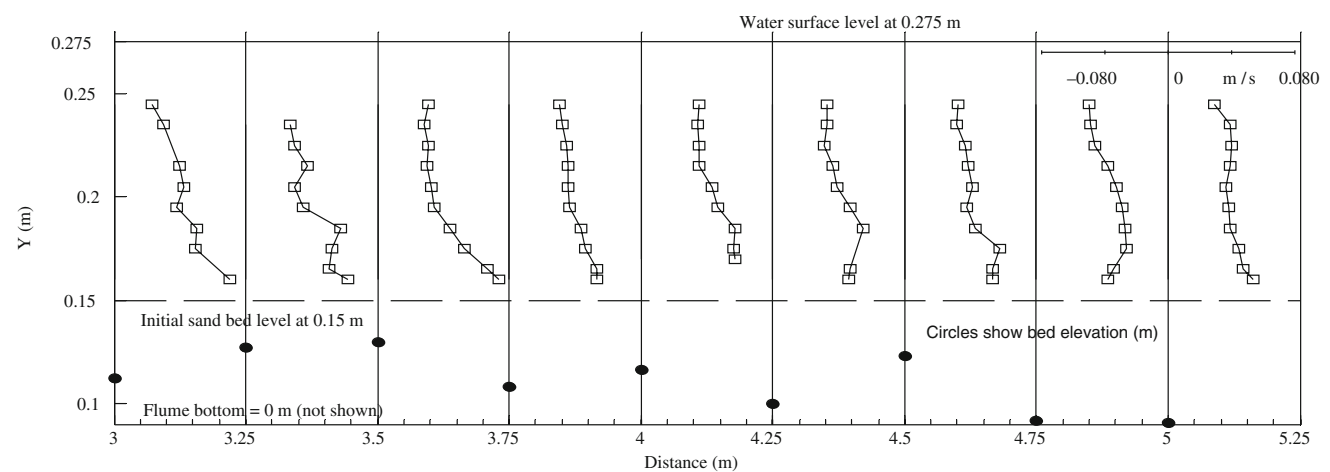

(b)

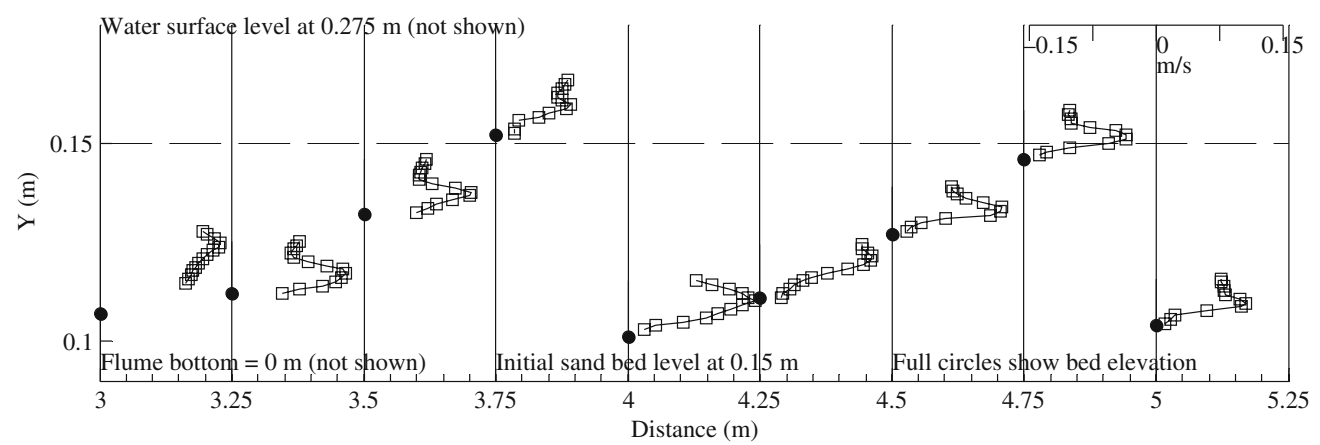

(c)

Figure 7. RMS velocities in streamwise direction (a) PRMB-1, (b) PRMB-2, and (c) PRMB-2ADVP.

\subsection{Turbulent kinetic energy (TKE)}

Plots of TKE distribution along the flow depth in PRMB-1, PRMB-2 and ADV down-looking profiler data (PRMB2ADVP) in similar experimental conditions of PRMB-2 are shown in figures 13(a), 13(b) and 13(c) respectively. TKE is related to the presence of suspended sediment load, intermittency of turbulence near bottom and turbulence production. Peak values of TKE are observed in the trough region and the reattachment point (figure 13c) due to the influence of velocity defect layer on the lee side of the dunes. However turbulent kinetic energy decreases along the stoss slope from reattachment region to dune crest (figure 13c). TKE peak magnitudes are comparable in PRMB-1, PRMB-2 and in PRMB-2ADVP experiments [see figures 13(a), 13(b) and 13(c)]. Throughout the depth, turbulent kinetic energy values are higher in PRMB-2 as compared to PRMB-1 where TKE is high only near the bed (figures 13a and 13b). It is observed that region of downward flow and TKE acting downward is extended across the dune wavelength (except flow separation region) and throughout the depth (refer figure 13a) due to increase in bedform roughness and bedform mobility.

\subsection{Time-space averaged turbulence quantities}

The velocity and turbulence field is spatially averaged with reference to the bed to minimize the errors caused by nonuniform flow over the mobile bedforms. Time averaged 


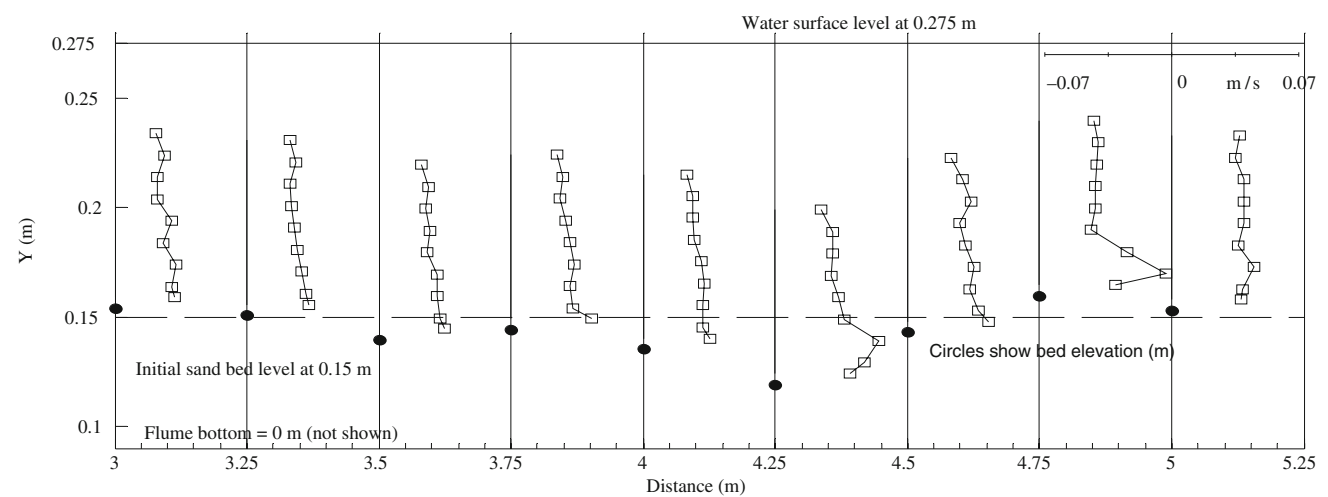

(a)

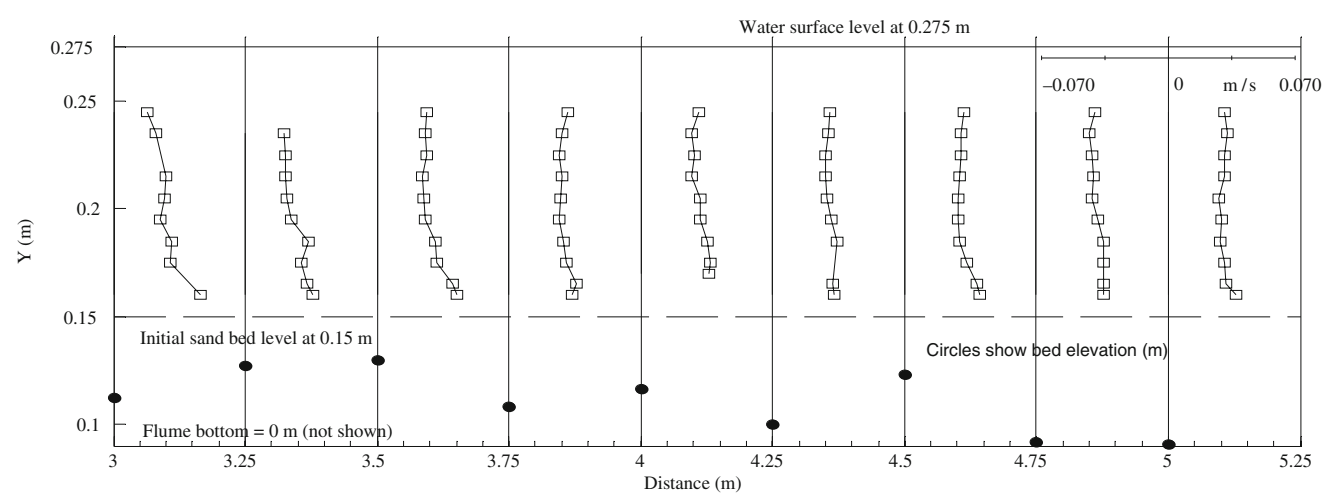

(b)

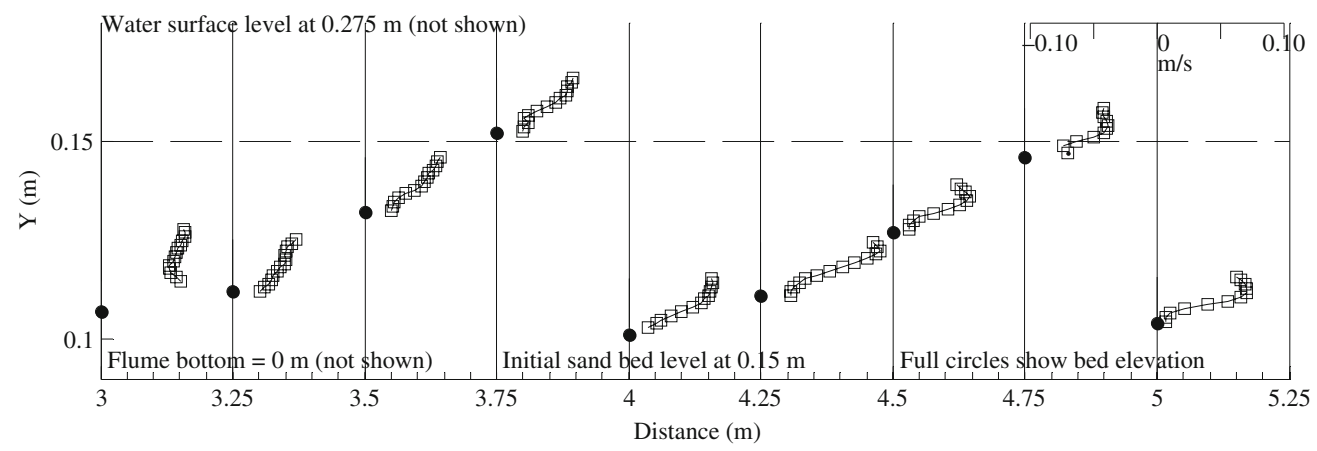

(c)

Figure 8. RMS velocities in transverse direction (a) PRMB-1, (b) PRMB-2, and (c) PRMB-2ADVP.

velocity and turbulence data have been spatially averaged over nine cross-sections in each experiment. Time-space averaged approach was used because continuous bedform movement rules out the comparison of individual time series at a point and also time averaged velocity profiles at verticals. It is very hard to get identical bedforms at positions where turbulence measurements are compared therefore time-space averaging has been adopted. Reynolds stresses, mean velocities, vertical and streamwise turbulent intensities and TKE are calculated from the time-space averaged data. Time-space averaged turbulence variables are compared between PRMB-1 and PRMB-2 in figure 14 for further discussion. Measuring 3D velocities near the bed in mobile bedforms is very difficult due to rapid changes in bed elevation and low visibility caused by the suspended sediment therefore near bed velocity measurements in experiment PRMB-2 are missing in figures 14(a)-14(i).

Profiles of the time-space averaged streamwise velocities normalized with respective maximum velocities in PRMB-1, PRMB-2 and immobile bed are shown in figure 14a. Dunes are moving with average velocities of $0.33 \mathrm{~cm} / \mathrm{s}$ and $0.51 \mathrm{~cm} / \mathrm{s}$ in PRMB-1 and PRMB-2, respectively. The flow velocity of PRMB-2 decreases near the bed as shown in figure 14a. The mobility of the 


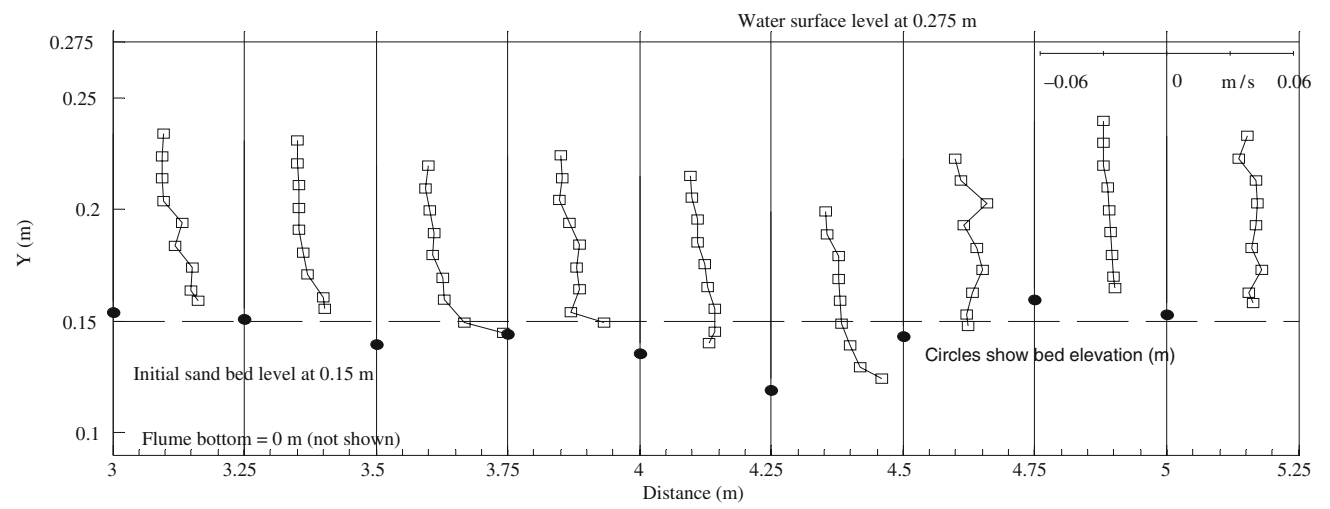

(a)

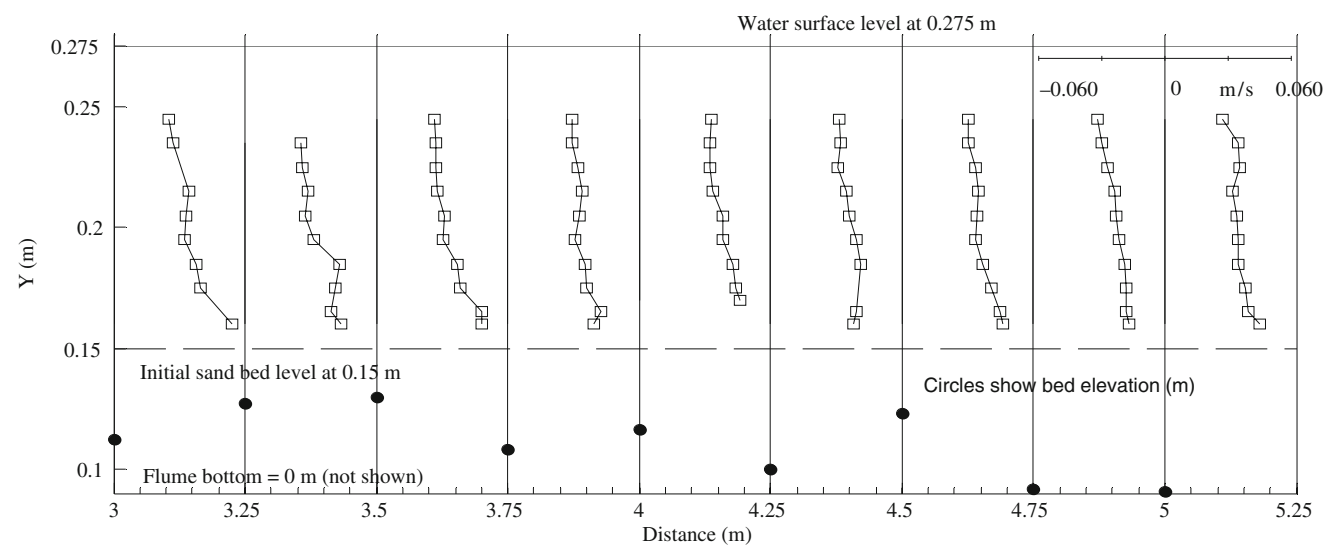

(b)

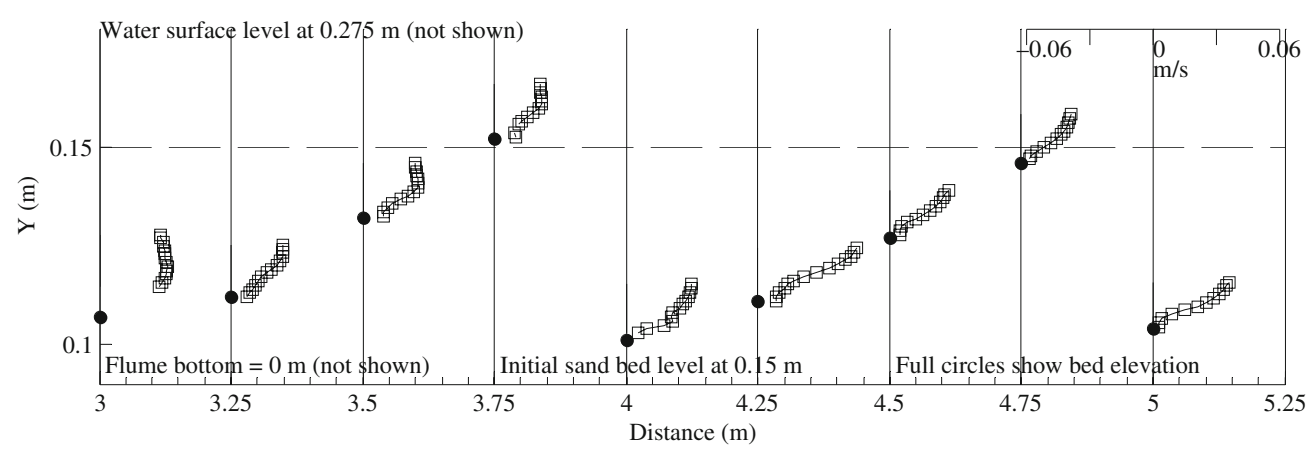

(c)

Figure 9. RMS velocities in vertical direction (a) PRMB-1, (b) PRMB-2, and (c) PRMB-2ADVP.

bedforms clearly influences the velocity distribution and increase in bed mobility causes an increase in bed friction as given in tables 2 and 3. Furthermore, the growth of bedforms depends on the increase in suspended sediment transport, which is known to increase the friction factor of the bed and reduces the velocity gradient of PRMB-2 near the bed.

The increase in flow velocity in PRMB-2 has increased suspended sediment load which causes the higher turbulence dampening and higher resistance to the flow, in feedback high turbulence intensities at the mobile bedforms increase entrainment of the sediment and increase size of the bedforms. Mobile bedforms experiments are compared with immobile bed (IM) experimental data, in which the velocity data was measured using a PIV and the details of the IM are already given. Only mean velocities, streamwise and vertical turbulence intensities and normalized streamwise Reynolds stresses are compared with immobile bed data since immobile bed data is available only in two dimensions. In all the comparisons between immobile bed and mobile bedforms, it is very clear that turbulence is very high on mobile bedforms. Normalized streamwise, 


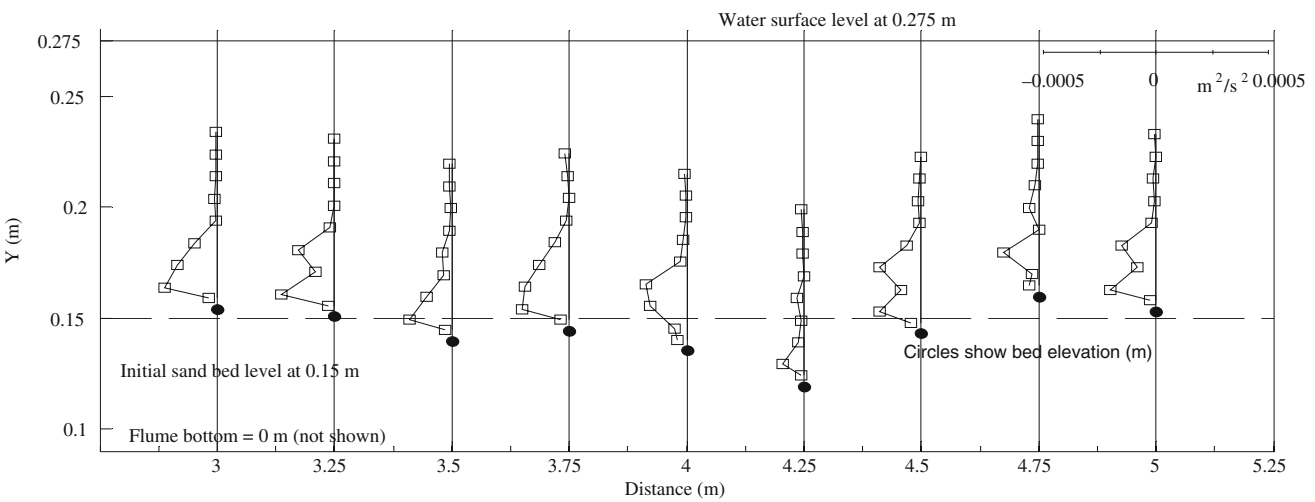

(a)

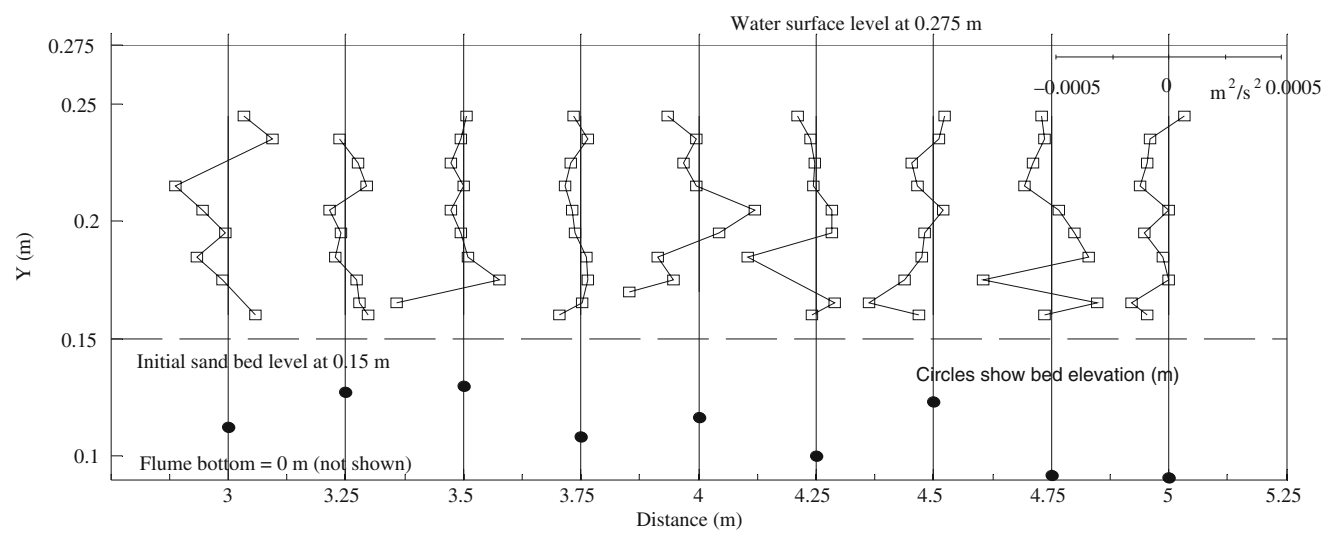

(b)

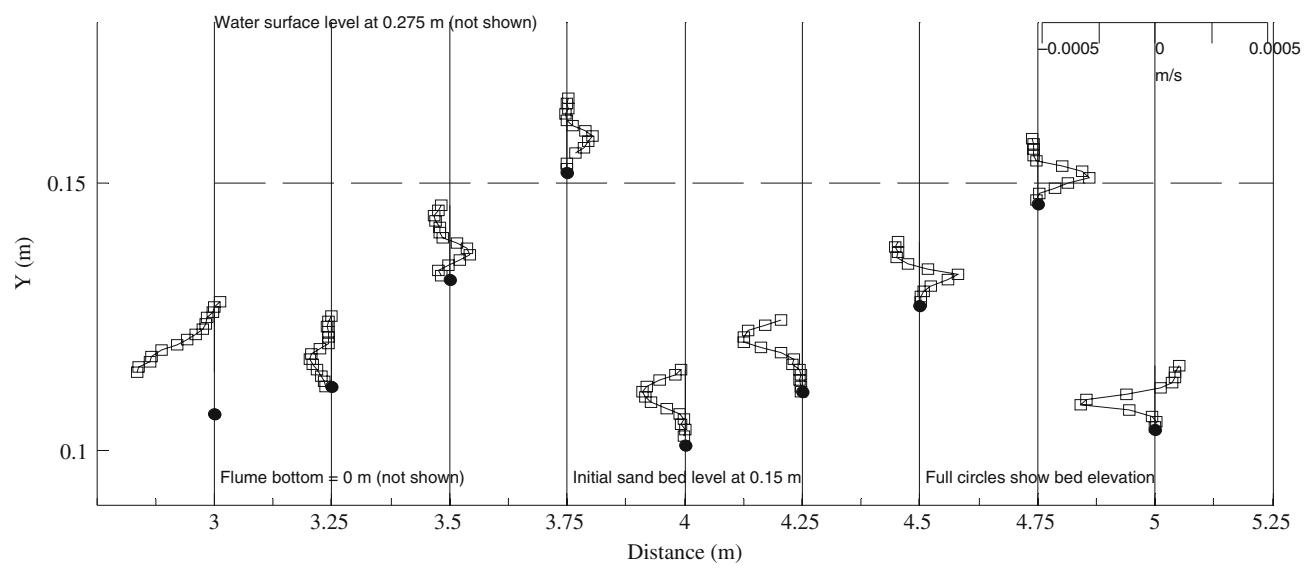

(c)

Figure 10. Reynolds shear stress $-\overline{u^{\prime} w^{\prime}}$ (a) PRMB-1, (b) PRMB-2, and (c) PRMB-2ADVP.

transverse and vertical turbulence intensities in experiments PRMB-1 and PRMB-2 are illustrated in figures 14(b)14(d), respectively. The peaks of the streamwise and vertical turbulence intensities in PRMB-2 are occurring farther from the bed as compared to PRMB-1 which confirms that the velocity defect layer and separated flow region is located slightly higher in flow over larger bedforms which indicates increased thickness of the roughness sublayer in PRMB-2. Even though the shape of the streamwise and wall normal turbulence intensity profiles are similar (figure 14b) for both mobile bedforms and immobile bed conditions, the streamwise and vertical turbulence intensities over mobile bedforms are higher in magnitude, especially within the roughness sublayer.

Three-dimensional turbulence intensities measured in experiments PRMB-1 and PRMB-2 are plotted in figure 14e. The turbulence intensities estimated are high throughout the depth in PRMB-2 caused by the increase in dissipation of momentum. It is observed that turbulence anisotropy is higher in PRMB-2 as compared to PRMB-1 


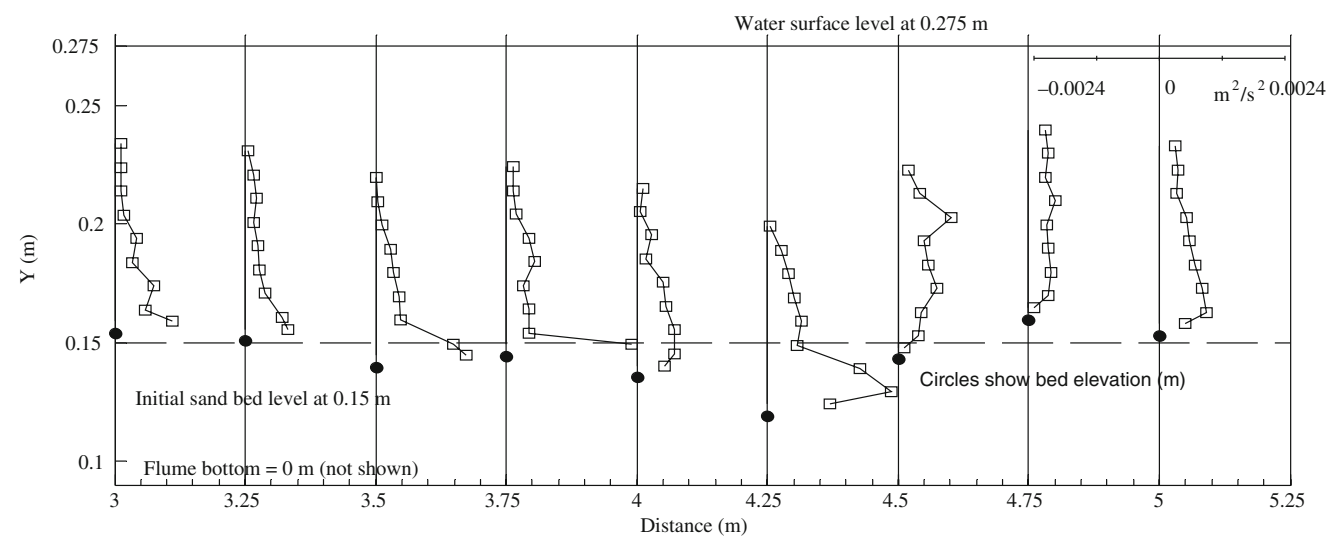

(a)

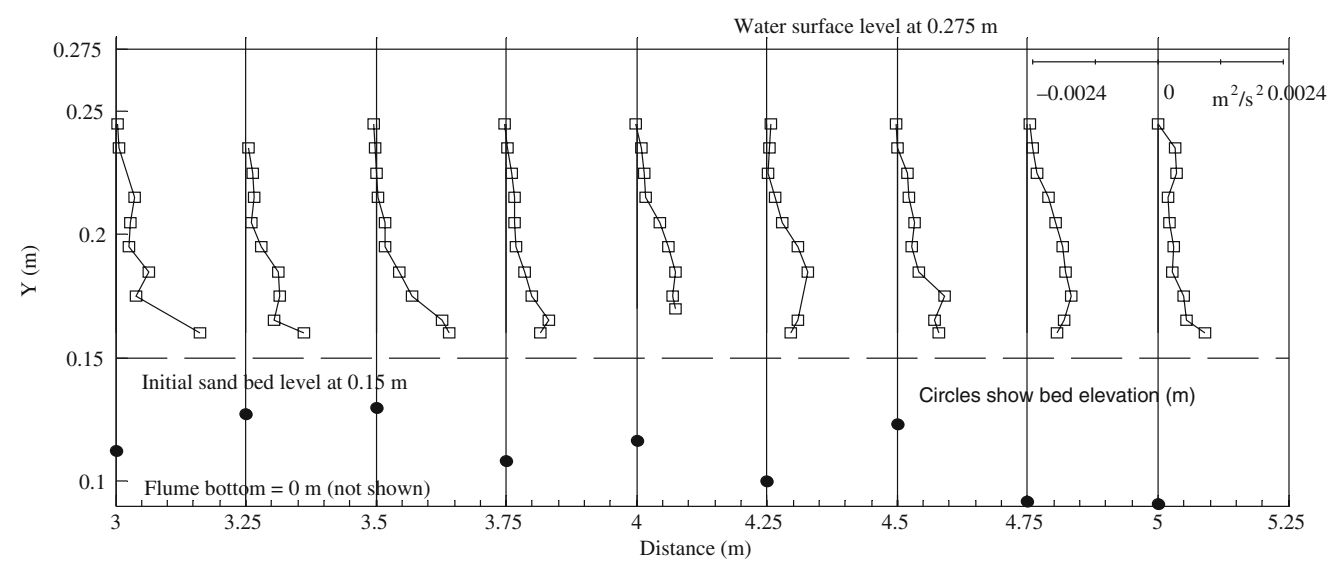

(b)

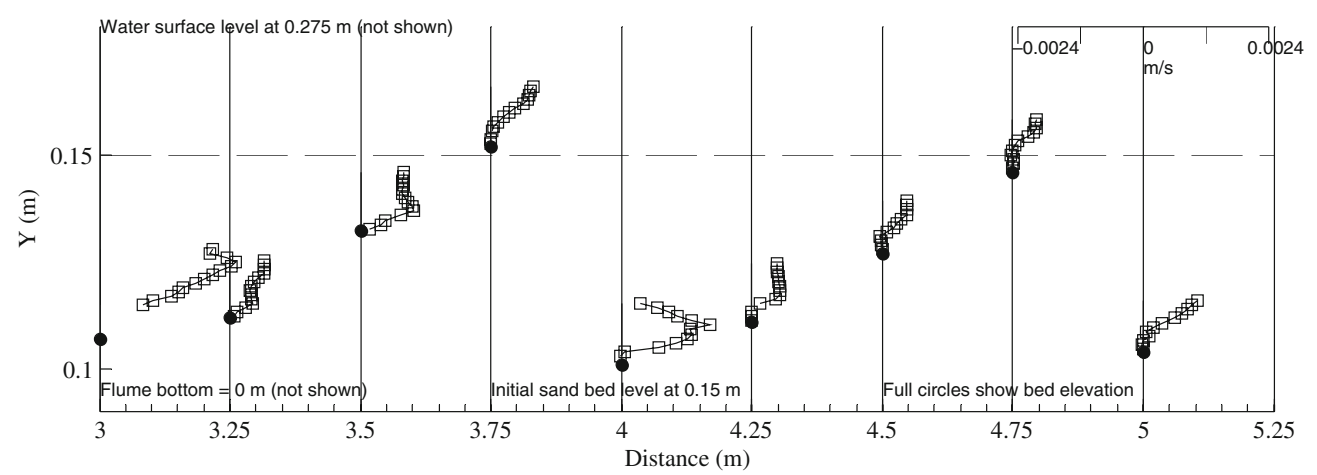

(c)

Figure 11. Reynolds shear stress $-\overline{u^{\prime} v^{\prime}}$ (a) PRMB-1, (b) PRMB-2, and (c) PRMB-2ADVP.

due to bigger and faster moving bedforms. The $\bar{u}_{\text {rms }} / \bar{v}_{\text {rms }}$ in PRMB-2 is found to be between 1.5 and 1.2, and similarly ratio of $\bar{u}_{\text {rms }} / \bar{w}_{\text {rms }}$ varies between 1.7 and 1.3 . Ratio of $\bar{u}_{\text {rms }} / \bar{v}_{\text {rms }}$ throughout the depth in PRMB-1 is found to be between 1.4 and 1.02 , and similarly ratio of $\bar{u}_{\mathrm{rms}} / \bar{w}_{\mathrm{rms}}$ varies between 1.5 and 1.1. Therefore, it is concluded that flow anisotropy is slightly increased from PRMB-1 to PRMB-2 as the dunes grow. The turbulent intensities and turbulence anisotropy penetrates throughout the depth in mobile bedforms and the flow field is found to be 3-D and non-uniform. Near the wall, flow produces turbulent bursting events which in turn increase the TKE as illustrated in figure 14(f). It is observed that the turbulent kinetic energy also increases as the dunes grow. Sumer et al [28] found the increase in turbulence intensities with increase in bed load transport and present experiments support this argument. The distributions of the normalized Reynolds stress components with respect to depth are shown in figure 14(g)-14(i). it is observed that the Reynolds stresses are increasing with increase in turbulence 


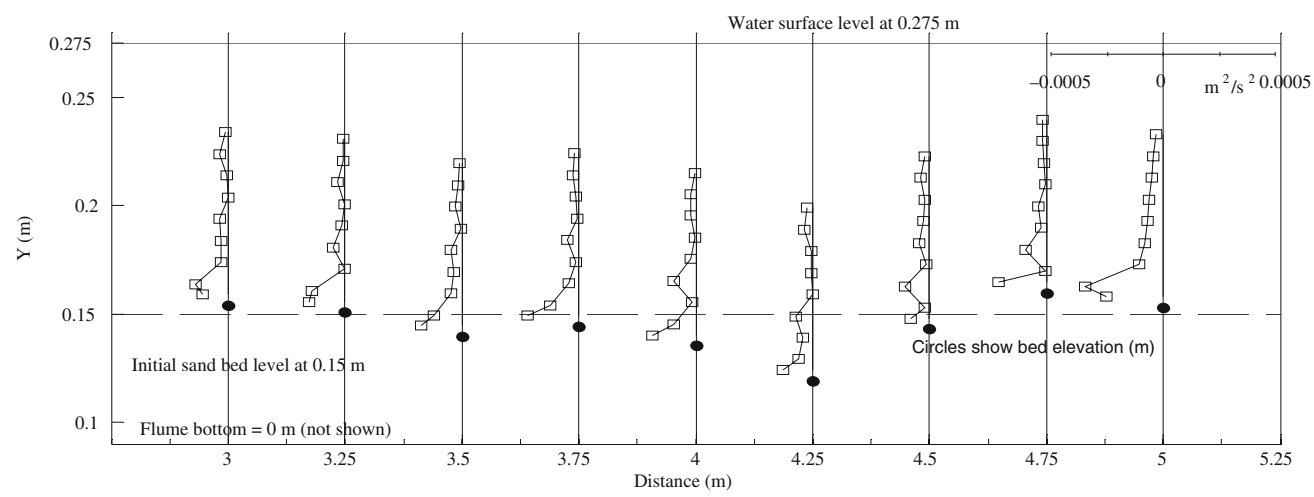

(a)

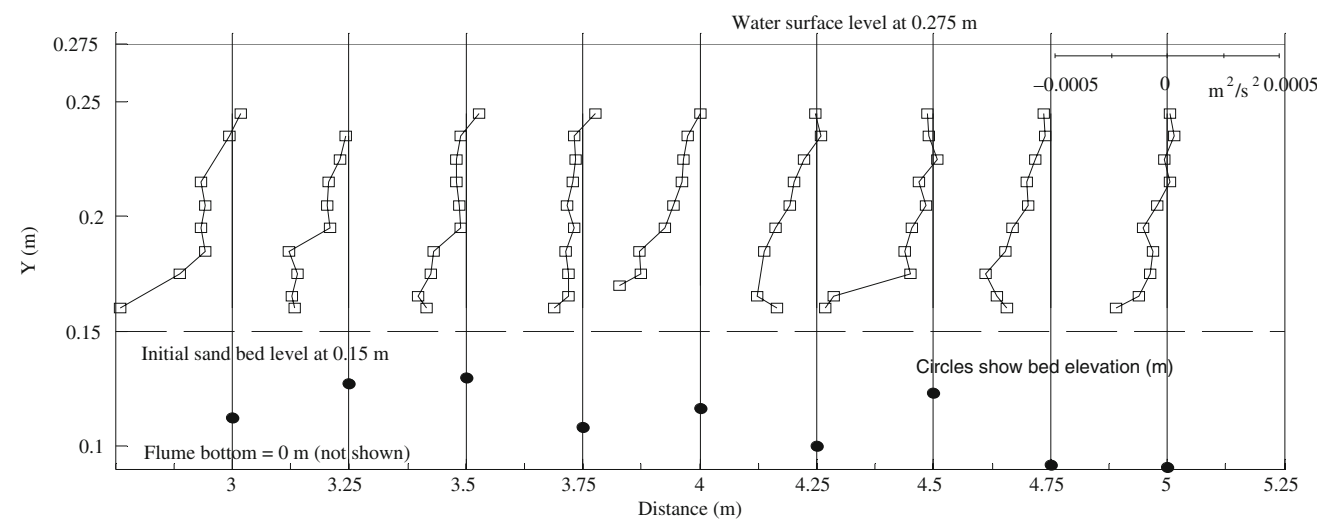

(b)

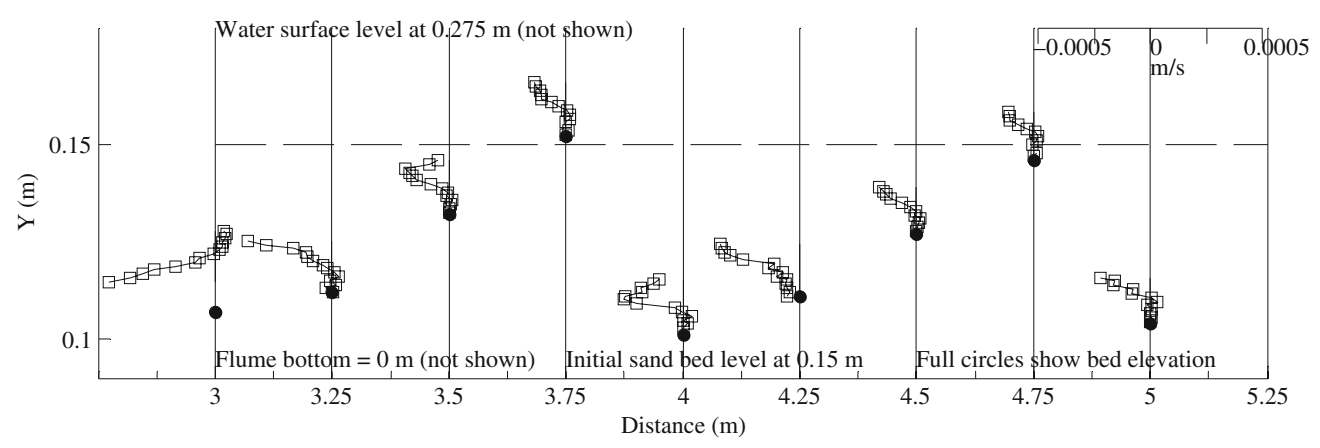

(c)

Figure 12. Reynolds shear stress $-\overline{v^{\prime} w^{\prime}}$ (a) PRMB-1, (2) PRMB-2, and (c) PRMB-2ADVP.

level near the wall due to increase in sediment transport. Comparison of vertical distributions of Reynolds stresses in PRMB-1 and PRMB-2 implies that Reynolds stresses increase as the dune size increases (figure $14 \mathrm{~g}$ ). Analysis of figure $14 \mathrm{~g}$ indicates a higher value of $-\overline{u^{\prime} v^{\prime}}$ on flow over mobile bedforms as compared to flow over immobile bed. Also significant increase in $-\overline{u^{\prime} v^{\prime}}$ from PRMB-1 to PRMB2 supports the concept of increased flow resistance (bed friction factor) and increased bed-load transport as the dunes grow. Figure 14(h) shows vertical profiles of normalized $-\overline{u^{\prime} w^{\prime}}$ which is not affected by increased size of the dunes as well as increased bedload.

\section{Conclusions}

In this paper, the main objective is to investigate the turbulence in open channel flows during the transient state of hydraulically rough porous mobile dunes. In this direction, profiles of streamwise velocities, turbulence intensities of streamwise, wall-normal and transverse velocities, Reynolds stresses of streamwise, wall-normal and transverse velocities in vertical direction have been investigated using time averaged and time-space averaged ADV velocity measurements along the depth over mobile dunes. It was assumed that the bed does not change significantly i.e., the 


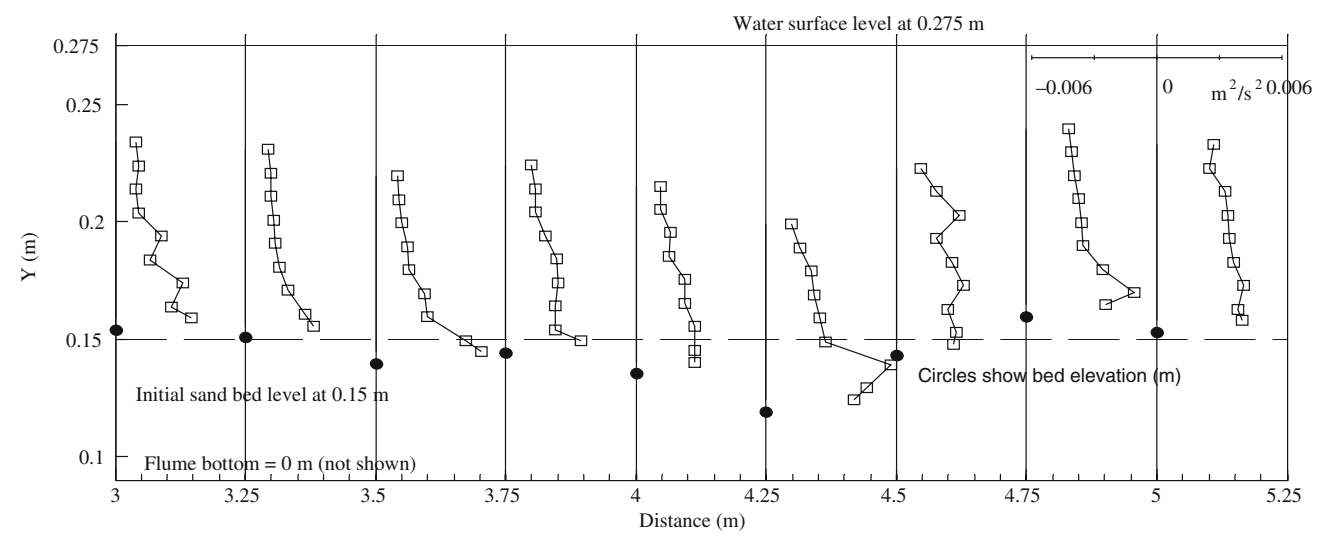

(a)

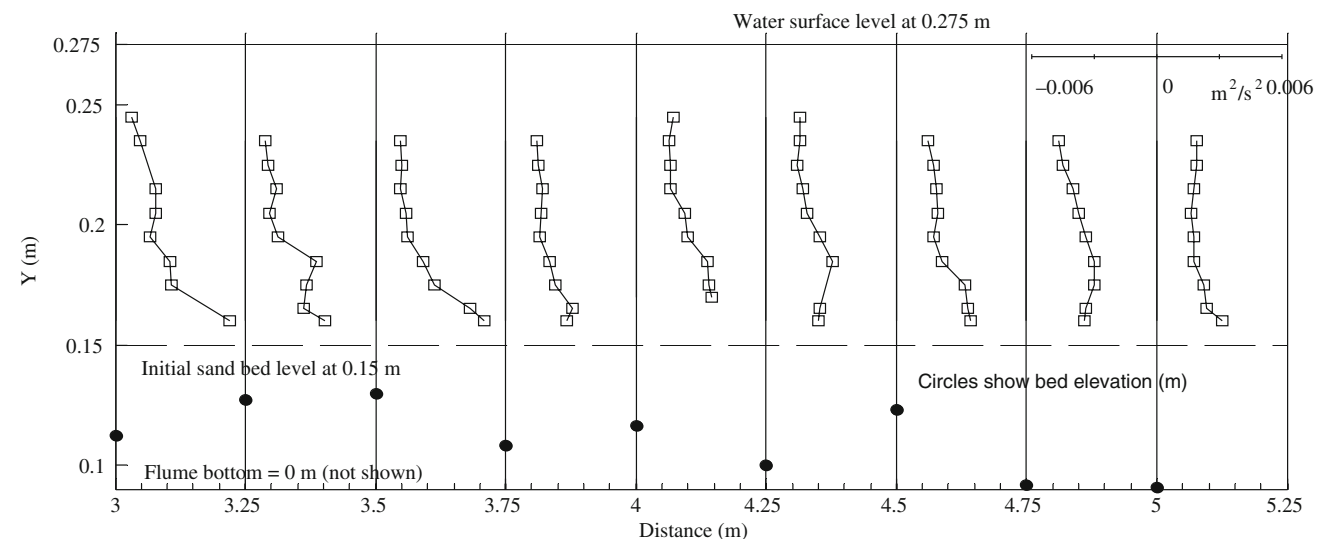

(b)

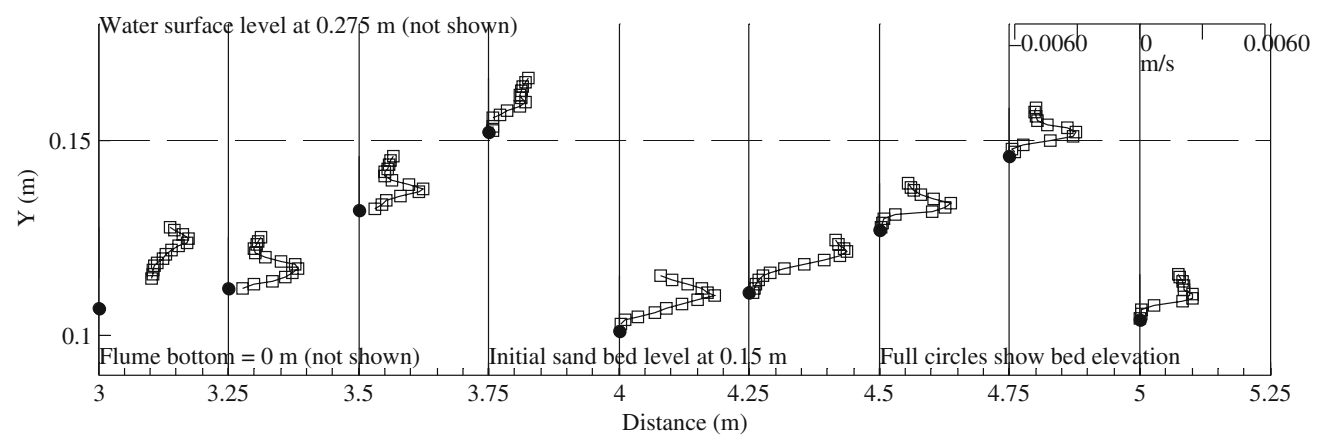

(c)

Figure 13. Turbulent kinetic energy (a) PRMB-1, (b) PRMB-2, and (c) PRMB-2ADVP.

quasi-stationary bed condition was assumed while measuring the velocity distribution along the depth. Experiments were conducted with two different flow conditions resulting in the formation of two different size mobile dunes. Dunes height, wavelength and velocity of dunes found to be increasing with increase in average flow velocity for a constant flow depth. However steepness factor of dunes did not get effected. Analysis of the velocity measurements in the present experiments demonstrated that the von Karman constant $(\kappa)$ diminishes when bedforms form and move along with the flow. The computed
Manning's roughness coefficients, skin friction coefficients and Darcy Weisback friction factors are increasing with increase in size and velocity of bedforms for a given constant flow depth. The magnitudes of transverse velocities are approximately $1 / 10$ of streamwise velocities and vertical velocities are approximately half of the transverse velocities. The considerable magnitudes of transverse velocities over mobile bedforms necessitate measurement of 3-D velocity components to analyze the flow field. Computed turbulence intensities are found to be maximum in the region consisting of the trough and the reattachment 


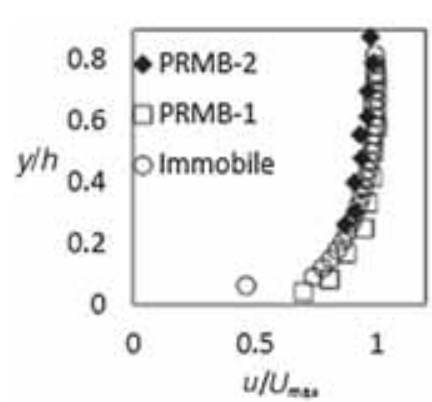

(a) Normalized streamwise velocity

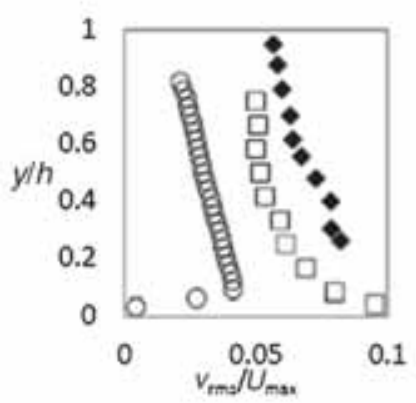

(d) Vertical distribution of normalized vertical turbulent intensity

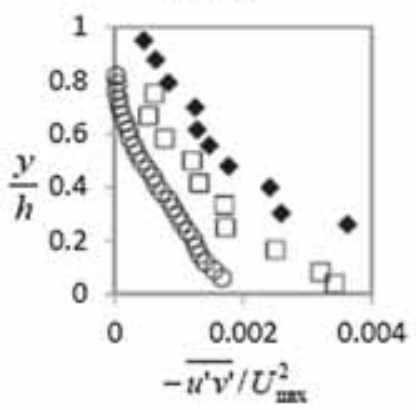

(g) Vertical distribution of nomalized streamwise Reynolds stress

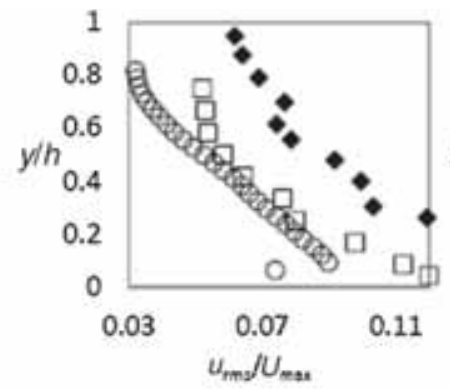

(b) Vertical distribution of nomalized stream- wise turbulent intensity

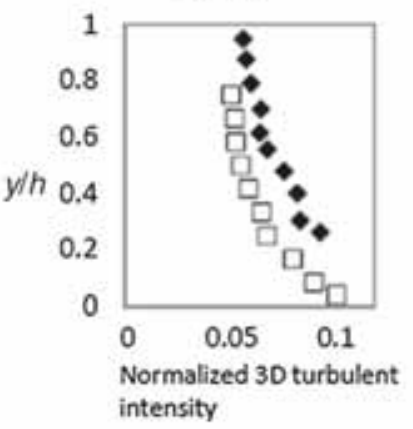

(e) Vertical distribution of normalized 3.D turbulent intensity

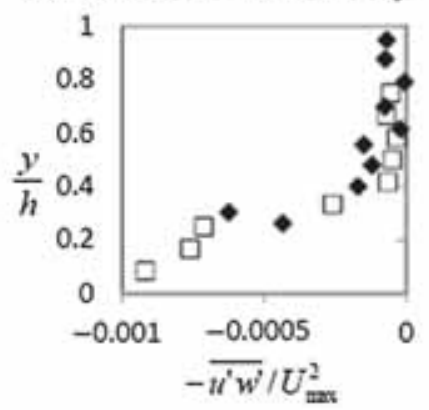

(h) Vertical distribution of normalized transverse Reynolds stress

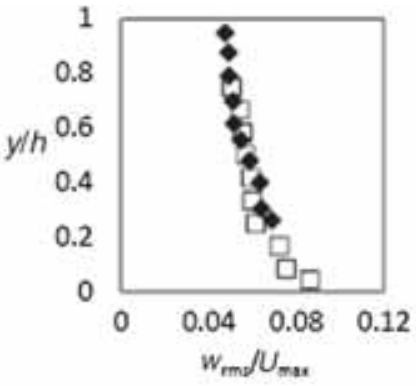

(c) Vertical distnibution of normalized transverse turbulent intensity

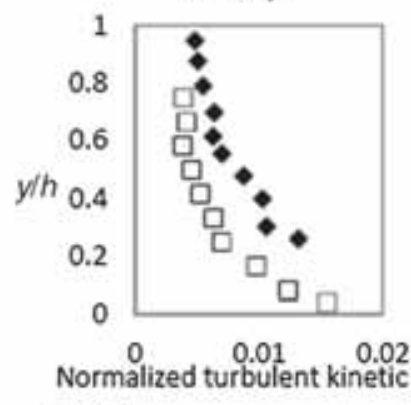

energy

(f) Vertical distribution of nomnlized turbulent kinetic energy

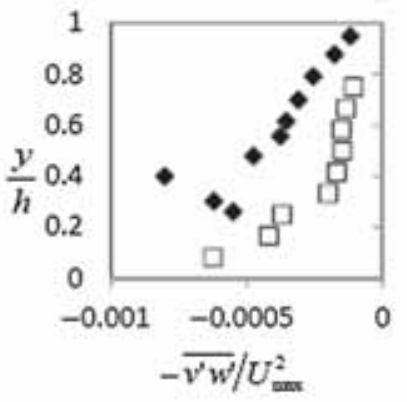

(i) vertical distribution of normalized Reynolds stress plane perpendicular to the flow

Figure 14. Comparison of time-space averaged turbulence quantities of experiments PRMB-1 and -2 .

point of the dunes. It is observed that streamwise turbulence intensities near the bed are twice the transverse turbulence intensities, and transverse turbulence intensities are twice the vertical turbulence intensities. Reynolds stresses (transverse fluxes of streamwise and vertical momentum) are observed to be high on mobile bedforms which shows mobile dunes reinforce the secondary currents. Peak values of turbulent kinetic energy (TKE) and Reynolds stresses are also found in the region consisting of the trough and the reattachment point. It is visually observed in the present experiments that maximum erosion takes place at the reattachment point and eroded sediment is carried as total load and dropped on the lee slope of the subsequent downstream dune. This phenomenon is caused by flow expansion in the separation zone, and which is also the main reason for mobility of dunes and associated bedload transport. Most importantly, it is found that turbulence anisotropy increases with increase in size of mobile bedforms and anisotropy is extended up to the free surface in the flows over mobile bedforms, which proves the entire depth of flow is being disturbed by the mobile dunes.

\section{Notations}

$d_{50}, d_{84}$ and $d_{16}$

the grain diameters at which 50, 94 and $16 \%$ of sediment is finer than this size, respectively 


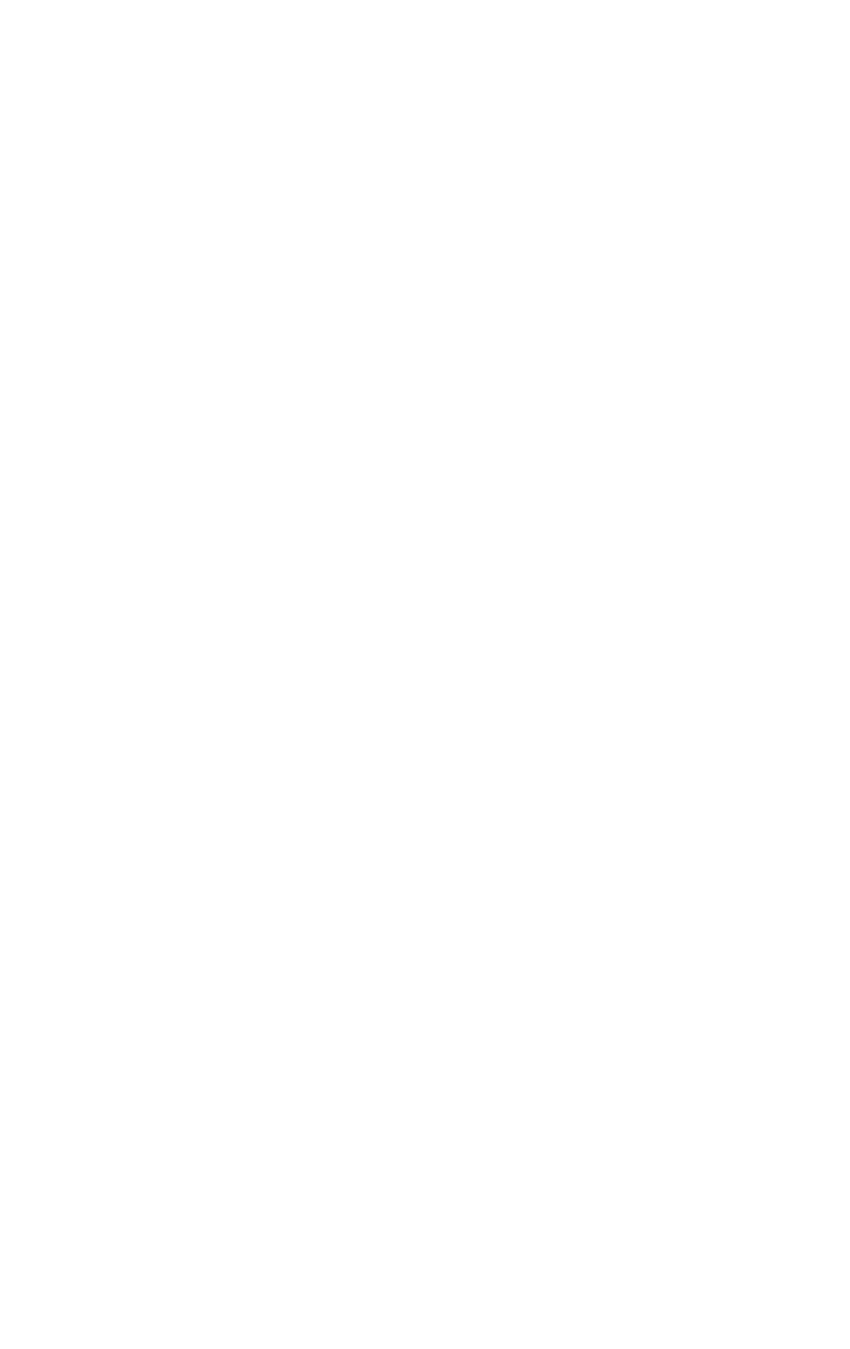

\section{References}

[1] Maji S, Hanmaiahgari P R and Subhasish Dey 2014 Experimental studies of local scour in the pressurized OCF below a wooden $\log$ across the flow. Sadhana 39(5): 1245-1257. DOI: $10.1007 / \mathrm{s} 12046-014-0267-0$

[2] Hanmaiahgari P R, Hanif Chaudhry M and Jasim Imran 2015 Computation of gradually varied flow in compound open channel networks. Sadhana 39(6): 1523-1545. DOI: 10. 1007/s12046-014-0299-5

[3] Bennett S and Best J L 1995 Mean flow and turbulence structure over fixed, two dimensional ripples: Implications for sediment transport and bedform stability. Sedimentology 42: 491-513

[4] Balachandar R and Patel V C 2008 Flow over a fixed rough dune, Can. J. Civil Eng. 35: 511-520

[5] Bennett S J and Best J L 1996 Mean flow and turbulence structure over fixed ripples and the ripple-dune transition. In: P J Ashworth et al (Eds) Coherent flow structures in open channels. pp. 281-304, John Wiley, Hoboken, NJ
[6] Best J L 2005 The fluid dynamics of river dunes: A review and some future research directions. J. Geophys. Res. 110: 1

[7] Balachandar R, Hyun B-S and Patel V C 2007 Effect of depth on flow over a fixed dune. Can. J. Civil Eng. 34: 1587-1599

[8] Balachandar R and Bhuiyan F 2007 Higher-order moments of velocity fluctuations in an open channel flow with large bottom roughness. J. Hydraul. Eng. 133: 77-87

[9] Robert A and Uhlman W 2001 An experimental study of the ripple-dune transition. Earth Surf. Process. Landforms 26: 615-629

[10] Coleman S E, Nikora V I, McLean S R, Clunie T M, Schlicke T and Melville B W 2006 Equilibrium hydrodynamics concept for developing dunes. Phys. Fluids 18(10): 105104-1-12

[11] Nikora V and Goring D 2000 Flow turbulence over fixed and weakly mobile gravel beds. J. Hydraul. Eng. 126(9): 679-690

[12] Bridge J S and Best J L 1988 Flow, sediment transport and bedform dynamics over the transition from dunes to upperstage plane beds: Implications for the formation of planar lamination. Sedimentology 35: 753-763

[13] Schindler R J and Robert A 2005 Flow and turbulence structure across the ripple-dune transition: An experiment under mobile bed conditions. Sedimentology 52, doi:10.1111/ j.1365-3091.2005.00706x

[14] Nikora V I and Goring D G 1998 ADV measurements of turbulence: Can we improve their interpretation. J. Hydraul. Eng. 124(6): 630-634

[15] Chanson H, Trevethan M and Aoki S 2008 Acoustic Doppler Velocimetry (ADV) in small estuary: Field experience and signal post-processing. Flow Meas. Instrum. 19(5): 307-313

[16] Goring D and Nikora V 2002 Despiking acoustic Doppler velocimeter data. J. Hydraul. Eng. 128(1): 117-126

[17] Wahl T L 2000 Analyzing ADV Data using WinADV. Joint Conference on Water Resources Engineering and Water Resources Planning and Management, American Society of Civil Engineers, July 30 - August 2, 2000, Minneapolis, Minnesota

[18] Wahl T L 2003 Discussion of despiking acoustic Doppler velocimeter data. J. Hydraul. Eng. 129(6): 484-487

[19] Mori N, Suzuki T and Kakuno S 2007 Noise of acoustic Doppler velocimeter data in bubbly flow. J. Eng. Mech. ASCE 133(1): 122-125

[20] Gyr A and Schmid A 1997 Turbulent flows over smooth erodible sand beds in flumes. J. Hydraul. Res. 35(4): $525-544$

[21] Song T, Graf W H and Lemmin U 1994 Uniform flow in open channels with gravel bed. J. Hydraul. Res. 32(6): 861-876

[22] Nezu I and Nakagawa H 1993 Turbulence in open channel flows. IAHR Monograph, Balkema, Rotterdam

[23] Krogstad P, Antonia R, and Browne L 1992 Comparison between rough-and-smooth-walled turbulent boundary layers. J. Fluid Mech. 245: 599-617.

[24] Holmes R R and Garcia M H 2008 Flow over bedforms in a large sand-bed river: A field investigation. J. Hydraul. Res. 46(3): 322-333 
[25] Balachandar R and Patel V C 2002 Rough wall boundary layer on plates in open channels. J. Hydraul. Eng. ASCE 128(10): 947-951.

[26] Raupach M R, Antonia R A and Rajagopalan S 1991 Roughwall turbulent boundary layers. Appl. Mech. Rev. 44: $1-25$
[27] Camenen B, Bayram A and Larson M 2006 Equivalent roughness height for plane bed under steady flow. J. Hydraul. Eng. 132(11): 1146-1158

[28] Sumer B M, Chua L H C, Cheng N-S and Fredsoe J 2003 Influence of turbulence on bed load sediment transport. $J$. Hydraul. Eng. 129(8): 585-596 